The International Journal of Flexible Manufacturing Systems, 1 (1989): 287-324

(C) 1989 Kluwer Academic Publishers, Boston. Manufactured in The Netherlands.

\title{
Algorithms for Efficient Planning and Operation of a Particular FMS
}

\author{
KATHRYN E. STECKE \\ University of Michigan, Graduate School of Business Administration, Ann Arbor, Michigan 48109
}

\begin{abstract}
This article is a detailed case study of a particular FMS that will be operational in 1989. It describes the daily planning and operating problems that will need to be addressed. The algorithms that will operate this system are presented. Given the daily changing production requirements, the algorithms begin with an aggregate planning feasibility check. Then planning, scheduling, inventory management, and breakdowns are addressed.

The key problems in operating this system are tool management problems. Detailed tooling data and their analysis are presented in an appendix to address these problems.
\end{abstract}

\section{Introduction}

A proposed COMAU-made FMS in Torino, Italy, will consist of six identical five-axis COMAU CNC machine tools, with three on both sides of a washing/inspection unit and refixturing spot. Each CNC has one input and one output buffer. See Figure 1 for the proposed layout. There will be two COMAU materials handling vehicles, one on each side of the central unit. The FMS will work three shifts and is expected to be in production sometime in 1989.

This article describes in thorough detail the actual FMS planning and operating problems of a particular FMS. The real need to use some operations research (OR) modeling and analysis tools is shown. This article provides several suggestions of how such a system might be operated. The complexity and levels of detail that need to be addressed in order to operate it effectively are provided. The detailed tooling data and their analysis presented here show how the loading problems can be simplified and sometimes solved manually.

In the remainder of this section, the details of the FMS are provided. The parameters and requirements from the system are outlined in Section 2 . Then some system particulars are noted that impose constraints on possible solutions to operate the FMS efficiently. In Section 3, we identify and provide definitions of the various planning and operating problems that need to be addressed. In Section 4, detailed algorithms are suggested that define how a given (and changing) daily mix of production requirements are to be manufactured efficiently. The algorithms are developed subject to the particular constraints of the Torino FMS that was designed to require a high system utilization in order to meet demand. Implementation of the algorithms is also discussed. Breakdown considerations are further discussed in Section 5. Future system and algorithmic requirements are indicated in Section 6. A summary is provided in Section 7. The Appendix contains tooling data that are used for component clustering based on tooling requirements. 


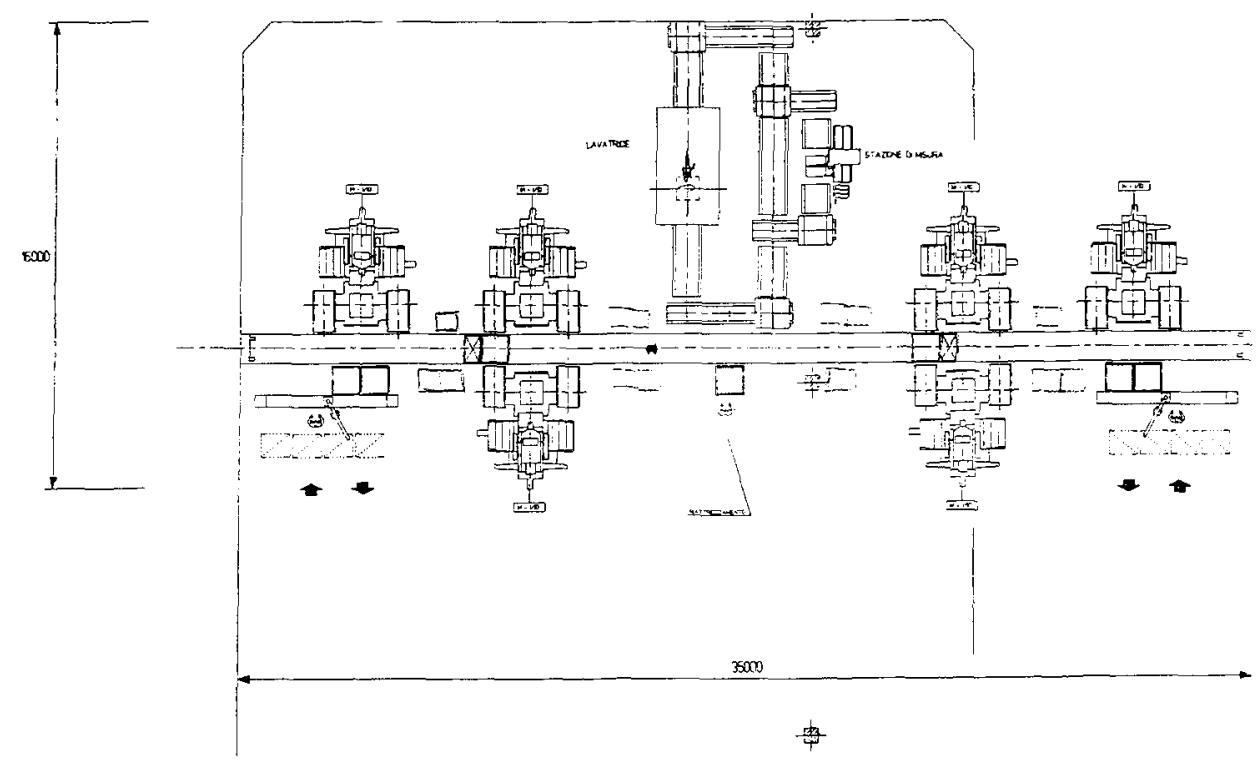

Fig. I. Layout of the COMAU Torino FMS.

Each machine has two primary tool magazines of sixty slots each. Primary means that the machine has direct access to both magazines. Then each machine tool has a tool magazine capacity of 120 slots, and each cell has a capacity of 360 slots.

Components for six different aluminum gearboxes will be machined on the FMS. The requirements of each gearbox can vary by 5-10 percent daily. In order to meet these requirements, the FMS requires an 80 percent system utilization, on average.

The FMS requirements for these six gearboxes consist of $2,2,2,2,3$, and 4 components, respectively, to result in a total of 15 part types to be manufactured on the FMS. There is some overlap in component requirements, so there are 12 unique components. Data on the components of the six gearboxes are given in Table 1.

To hold these 15 part types, four fixture types are required. Each fixture can hold only one part at a time. A closed queueing network (CQN) analysis (Menga et al. 1984) determined that there should be $10,13,2$, and 4 fixtures, respectively, of each fixture type. The CQN model is based on mean value analysis (see Reiser and Lavenberg 1980; Cavaillé and Dubois 1982; and Suri and Hildebrant 1984, for example).

Fixture types 2 and 4 require some time to set up the fixture if it is to hold a new part type. There is one fixture setup station in the central unit, so that only one fixture can be set up at a time. Fixture setup takes about ten minutes and is done manually. The following is additional fixturing information: 
Table 1. Gearbox data

\begin{tabular}{|c|c|c|c|c|c|}
\hline \multirow{2}{*}{$\begin{array}{l}\text { Operation } \\
\text { number }\end{array}$} & \multirow{2}{*}{$\begin{array}{c}\text { Gearbox } \\
\text { (housing) }^{b}\end{array}$} & \multirow{2}{*}{$\begin{array}{c}\text { Part type } \\
\text { description }\end{array}$} & \multirow{2}{*}{$\begin{array}{c}\text { Fixture } \\
\text { type/setup }\end{array}$} & \multicolumn{2}{|c|}{ Cell } \\
\hline & & & & & B \\
\hline & 1[2]: & & & & \\
\hline 1 & $1-1$ & (1) Carter and Front Box (Cover) & $1 / 1$ & $x$ & \\
\hline \multirow[t]{2}{*}{2} & $1-2$ & (2) Half Box Rear (Case) & $2 / 1$ & & $\mathbf{x}$ \\
\hline & $2[2]:$ & & & & \\
\hline 3 & $2-1$ & (1) & $1 / 1$ & $\mathbf{x}$ & \\
\hline \multirow[t]{2}{*}{4} & $2-2$ & (2) & $2 / 1$ & & $x$ \\
\hline & $3[2]:$ & & & & \\
\hline 3 & $3-1$ & (1) & $1 / 1$ & $\mathrm{x}$ & \\
\hline \multirow[t]{2}{*}{5} & $3-2$ & $(2)$ & $2 / 1$ & & $x$ \\
\hline & $4[2]:$ & & & & \\
\hline 6 & 4-1 & (1) & $1 / 1$ & $\mathrm{x}$ & \\
\hline \multirow[t]{2}{*}{7} & 4-2 & (2) & $2 / 2$ & & $\mathrm{x}$ \\
\hline & $5[3]:$ & & & & \\
\hline 3 & $5-1$ & (1) & $1 / 1$ & $\mathbf{x}$ & \\
\hline 8 & $5-2$ & Intermediate Box & $2 / 3$ & $\mathrm{x}$ & \\
\hline \multirow[t]{2}{*}{9} & $5-3$ & Reduction Half Box Rear & $4 / 2$ & & $\mathbf{x}$ \\
\hline & $6[4]:$ & & & & \\
\hline 10 & $6-1$ & Intermediate Box & $2 / 3$ & $\mathbf{x}$ & \\
\hline 11 & $6-2$ & Friction Housing & $3 / 1$ & & $\mathbf{x}$ \\
\hline 12 & $6-3$ & Half Box Clutch Front & $4 / 1$ & & $x$ \\
\hline 9 & $6-4$ & Reduction Half Box Rear & $4 / 2$ & & $\mathrm{x}$ \\
\hline
\end{tabular}

${ }^{a}$ Our numbering of the twelve unique components.

${ }^{b}$ The number of components required for cach gearbox is in brackets.

This is an initial allocation of components to cells that balances workload based on average daily requirements.

Fixture type 1 can hold all five Carter and Front Box components with no fixture setups. Fixture type 2 can hold six components: four Half Box Rear components (three on one setting, one on another) and two Intermediate Box components that require a third fixture setup.

Fixture type 3 holds one component, the Friction Housing.

Fixture type 4 holds three components: one Half Box Clutch Front component on a first setting and two Reduction Half Box Rear components on the second setting.

The processing of each of the 15 components occurs on one mount only. They are in effect single operation parts. No refixturing is required. However, for some components, a fixture has to be set up. The processing of each component consists of loading, machining, washing, measuring, and unloading.

\section{System requirements and constraints}

The six gearboxes and 15 components are required in varying production volumes daily for input to a gearbox assembly line (and subsequently, to a truck assembly line). The 
daily gearbox assembly schedule is firm for one week in advance, for a week. The gearbox assembly line will work two shifts. The FMS will work three shifts for five days per week. Components machined in a job shop as well as bought components will also feed the gearbox assembly line. The FMS can work on weekends, if there are production problems. Some additional constraints of this FMS are the following:

1. The FMS can be effectively decomposed into two FMSs, called cells A and B, each consisting of the three $\mathrm{CNC}$ machine tools on either side of the central station. Some reasons for this include tooling considerations; the fact that each component consists of only a single operation; workload considerations; transport issues; and fixture and setup considerations. Then components will need to be allocated among the cells and then to one or more machine tools within the selected cell.

2. Each of the two carts will be dedicated to one of the triplets of machine tools on either side of the central washing/inspection/fixture setup operations. One reason for this is the speed of the carts. Another reason is to avoid cart congestions and traffic control. Because each component requires only a single machining operation using many cutters, movement between the two cells is unnecessary. The two carts on a rail can handle the traffic requirements. The remaining cart control functions will be detailed elsewhere.

3. Because of limited floor space, only a few part types can be machined at either cell at any moment of time. Raw castings will arrive in containers in small batches of size $b$. There is not enough space for many of these containers in front of the machine tools. On the other hand, a variety of part types will be produced simultaneously. Enough different part types must be produced to achieve an adequate system and fixture utilization.

4. Although the FMS is flexible enough to machine in batches of size 1, larger batches may have to be produced. The assembly line may produce in small batches of only one gearbox type at a time. Also, the raw castings storage containers hold a particular number of parts and will be returned to the warehouse empty after delivering the raw materials. These storage containers need to be filled. Finally, output storage containers will have a certain capacity and will also have to be filled. Then the FMS may produce some components in batches of some unknown size $b$. This batching constraint is not certain at the moment and might be relaxed after the final layout and parameters of the assembly line and FMS have been decided.

5. Because the FMS will fill requirements for components of gearboxes, perhaps in batches of size $b$, the six types may not all be produced every day. If they were, the machine tools might have to work at a very high utilization or there might not be enough system capacity on some days. The high utilization requirement is only cutting time and does not allow any idle time for travel, load/unload, fixture setup, and most importantly, breakdowns of any type (such as machine, spindle, or cutter).

6. Several part types share fixtures, which sometimes require a setup between different components. Therefore, fixtures need to be allocated to part types over time, and fixture usage and changeover scheduled. Some fixtures are a scarce resource in the system, and care must be taken in controlling the part type mix in the system so as to use several particular fixture types simultaneously. 
7. A main requirement is to deal with both daily mix changes and random breakdowns of varying duration.

8. A goal is to produce these gearbox batches just-in-time, if feasible.

9. The FMS will not carry any inventory for safety stock purposes. However, some inventory of some components or gearbox types has to be carried by the assembly line to smooth the customer orders with the potentially required batch sizes and to help meet requirements in breakdown situations. Also, because of daily mix changes, FMS capacity (in terms of machine time in a day) may sometimes not be enough. An inventory management policy must be specified to meet requirements on days when the FMS has insufficient machining capacity.

\section{Planning and operating problems}

An initial solution to one of the planning problems-allocating components to cells-was determined by an outside consulting firm. The solution was based on an initial estimation of an average part mix derived from projected annual volumes. Tool magazine capacities; average component batch processing times; fixture sharing, changing, and scheduling were considered. The solution consisted of allocating each component to one of the two cells so as to balance the two average cell workloads as much as possible. This initial fixed allocation is shown in Table 1.

Of course, such a fixed allocation cannot work in practice. First, because of the daily mix changes and the resultant variability in component total processing times, the total workload on each cell would change every day with such a fixed allocation. Bottleneck cells and machines will change. Indeed, on some days the fixed allocation would not be feasible. Second, machine breakdowns could not be handled easily and would cause severe production problems. Third, such a solution ignores the potential $b$ batch size constraint.

What is needed is a more flexible approach to allocate the changing workloads of the daily changing mix of components. A flexible approach is needed in order to handle uncertainties such as unexpected breakdowns, yield problems, daily mix changes, tool changes, fixture setups, and the like. The problems that need to be solved every day, after receipt of the day's production requirements, are largely production planning problems. These daily problems are identified as follows:

1. Part type selection. Based on both the daily requirements of the assembly line and the current inventory of components and gearboxes, the types of components and gearboxes that will be produced must be selected. This will sometimes be four or five of the six gearbox types. On some days, all six part types will be selected.

2. Batch size determination. The number of required parts of each of the selected gearbox types must be determined. This number may or may not be a multiple of $b$, depending on the actual output container size, the on-hand inventory, capacity, and yield issues.

3. FMS grouping. The machines within each cell can be partitioned into identically tooled machine groups. Machines within a particular machine gruop are said to be pooled and can perform the same operations during real time. Alternatively, if two machines are not identically tooled, but can perform some of the same operations, these machines are said to be partially pooled. 
4. FMS loading. Every component of the selected gearbox types must be allocated both to one of the cells and to one or more machine tools in a cell. Since the due date for all part types is that day, the objective used to help achieve the daily due date is to maximize machine utilization. This problem is approached in two ways: by allocating components so as to balance machine workloads; and by allocating components subject to the machine capacities, both time and tool magazine. The loading problems are as follows:

4a. Cell loading. Allocate the required components and associated cutting tools to one of the two cells so as to balance cell workloads or just remain feasible, subject to time and tool magazine capacity constraints.

4b. Machine loading. Within each cell, allocate each of the required components to one or more of the three machine tools so as to balance machine workloads or just remain feasible, subject to time and tool magazine capacity constraints.

These two loading problems can be solved sequentially, iteratively, or simultaneously. Important factors to consider are the similarities among some components, cutting tool duplication, and fixture requirements, capacities, and setup. Machines may be pooled and components' cutter assignments may be duplicated.

5. Fuxture allocation and use. The limited number of fixtures of the different fixture types need to be allocated among the part types for a period of time. Fixture setups need to be phased and sequenced, near the completion of some component's daily requirements.

6. FMS scheduling. The batches of the selected part types must be scheduled for input into the system throughout each day.

7. Inventory policies. In addition to the daily requirements, some inventory should be kept, to cover uncertainties such as unexpected breakdowns and daily mix changes. Safety stock will not be carried, but spare time at the end of a day should be used to begin the next day's requirements.

\section{Algorithms to solve the FMS planning and operating problems}

When solving these daily problems, there are some important considerations. In general, those components that require a particular fixture/setup combination are of the same family and tend to use many of the same tools. They should be allocated to one or more machine tools of the same cell. This saves tool magazine slots and tends to maximize the amount of cutting tool duplication. The suggested approaches to solve planning problems are now provided.

\subsection{Part type selection (PTS) and batch size determination (BSD)}

The FMS may not always have a large enough capacity every day to produce all part types. Therefore, some subset of the gearbox types may need to be selected to be produced each day. An inventory of gearboxes and components for the assembly lines should be carried in order to meet their daily requirements and to cover breakdowns and other uncertainties. 
The gearbox types should be selected to tend to decrease both the number of tool changes and the number of fixture setups.

The daily production requirements for gearbox $i$ consists of the planned gearbox production for the next day, which may also account for the potential backlog if any machines have been down for a period of time. Also, if there is time remaining, there should be some production during the remainder of day $n-1$ of the assembly requirements for day $n+1$. The requirements for the gearboxes provide the requirements for the components. Finally, the requirements may have to be rounded up as an integer multiple of the potential required batch size.

Notation for the following series of algorithms is defined in Table 2. Some additional notation will be required later.

Table 2. Notation

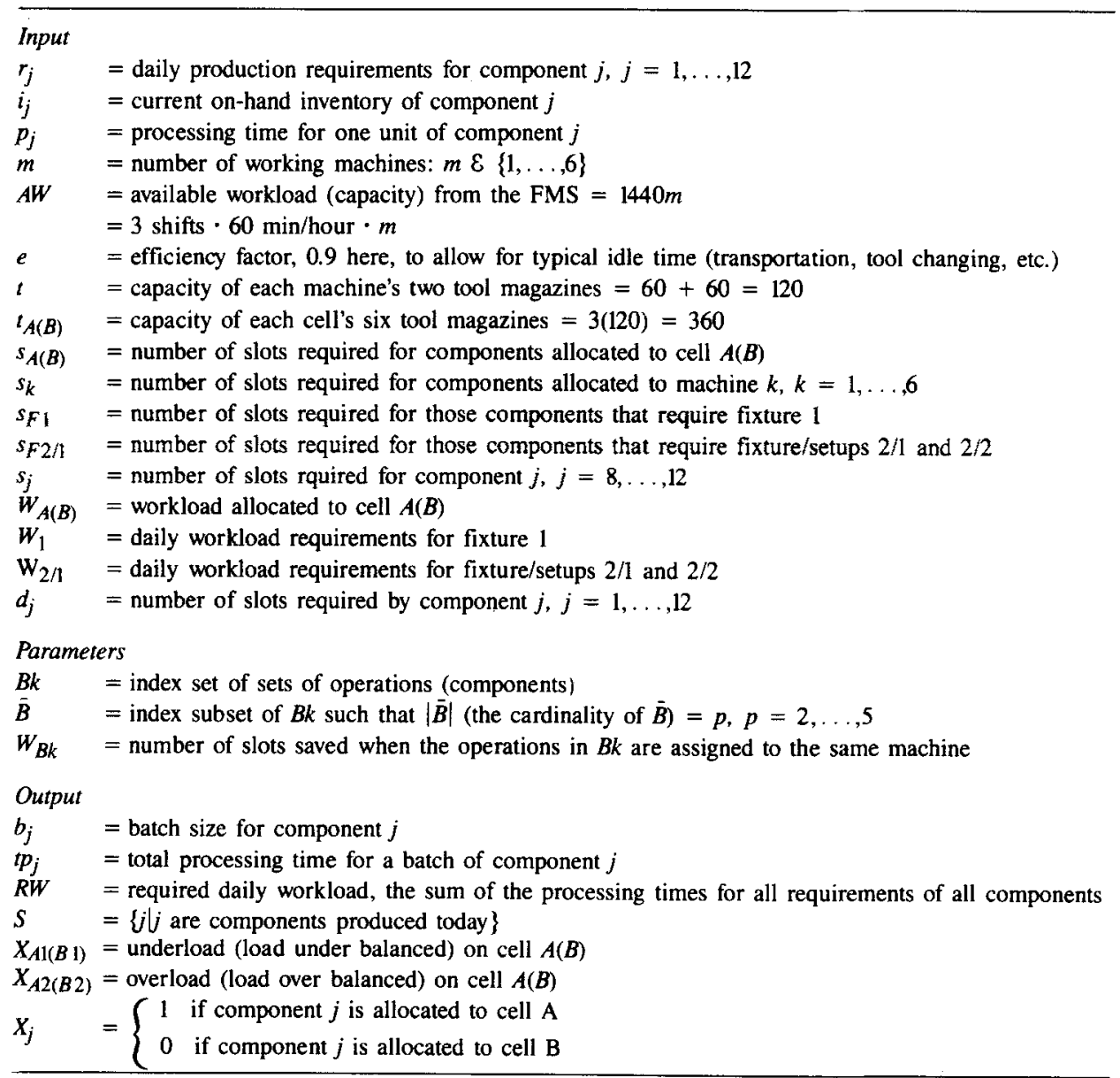


The algorithm to select part types and determine the day's batch sizes is:

\section{Algorithm for PTS/BSD}

Step 1. Calculate $r_{j}-i_{j}, j=1, \ldots, 12$. Those components $j$ such that $r_{j}-i_{j} \leq 0$ are not selected to be produced. Those $j$ such that $r_{j}-i_{j}>0$ are selected to be produced and are initially members of the set $S$. The batch size for component $j, j \in S$, is

$$
\max \left\{0, b_{j}=r_{j}-i_{j}\right\}
$$

Step 2. Calculate $t p_{j}=b_{j} p_{j}$ for all $j \epsilon S$.

$$
\begin{aligned}
& R W=\sum_{j \epsilon S} t p_{j} \\
& A W=e 1440 m .
\end{aligned}
$$

If $R W>A W$, go to step 3. If $R W \leq A W$, stop. Components $\{j \mid j \in s\}$ are produced. The rest are not.

Step 3. All required components cannot be produced, because of insufficient machine capacity. Calculate $R W_{j}=R W-t p_{j}$ for every $j \in S . R W=\max _{\mathrm{j}}\left\{R W_{j} \mid R W<\mathrm{AW}\right\}$ if this maximum exists. Otherwise, $R W=\max _{j}\left\{R W_{j}\right\}$. Component $\mathrm{j}$ is not produced. Remove $j$ from $S$.

Step 4. If $R W>A W$, select the next component to not be produced. An attempt should be made to select one required for some gearbox for which another component could not be produced. Go to step 3. If $\mathrm{RW} \leq \mathrm{AW}$, stop. The components $j, j \in S$, are produced.

Usually, there should be capacity to produce the requirements. When there is not, some components may be produced in a job shop or on the FMS over a weekend. If the final assembly schedule can accommodate changes, the component orders can be backlogged.

The spare time at the end of each day should be used to begin requirements for the following day or two, to buffer against uncertainties. This is detailed in Section 4.5. Planning for the potential production for inventory should be done midway through the day, for purposes of ordering the raw materials. Scheduling the production of the inventory should not begin until it is clear that the daily requirements will be met.

\subsection{FMS loading}

Each gearbox consists of 2, 3, or 4 components which need to be allocated first to one of the two cells and then to one or more machines within the appropriate cell subject to tool magazine capacity and workload balancing. The main constraints of this system arise 
from tool magazine capacity; therefore, the main problem is a loading problem. (See, for example, Berrada and Stecke 1986; Carrie and Perera 1986; and Stecke 1983; 1985.) The following suggested solution approaches resulted in part from the processing and analysis of the tooling data, which are provided in the Appendix. However, the data are not complete at present, so the solution approaches had to be more general than those suggested by the data in the Appendix. At the same time, the algorithms had to consider what was known about the tooling needs, such as the high overlap in tooling requirements for similar components.

4.2.1. FMS cell loading. There are three suggested algorithms to allocate components and tools to cells (and machines). Each could be used under different circumstances.

\section{Algorithm 1 for FMS cell loading}

Step 1. Calculate $\sum_{j} t p_{j}=W_{1}$ for those components that require fixture $1(\epsilon\{1,3,6\})$ and allocate this workload to cell $A$. The number of tool slots required for these operations, $s_{F 1}$, will range from 48 to 64 slots, depending on which gearbox types have been selected. (This allocation arises from the high overlap in cutters for these three components. Any one alone takes 48 slots, yet all together take only 64 slots.) The result is that $\leq 5$ of the 15 components or $\leq 3$ of the 12 unique components are arbitrarily allocated to cell $\mathrm{A}$.

Step 2. Calculate $\Sigma_{j} t p_{j}=W_{2 / 1}$ for those components that require the first or second setup of fixture $2,2 / 1$, and $2 / 2,(\epsilon\{2,4,5,7\})$ and allocate this workload to cell $\mathrm{B}$. The number of tool slots required for these operations, $s_{F 2 / 1}$, will range from 55 to 65 slots, depending on which gearbox types have been selected. The result is that $\leq 3$ of the 15 (and 12 unique) components are arbitrarily allocated to cell $\mathrm{B}$.

This leaves some subset of components $8,9,10,11$, and 12 to allocate to one of the cells. The allocation of these will differ from day to day and will be a function of the number of up machines, the gearbox types selected, and the production requirements, which will determine the workload requirements of each component.

Step 3. Calculate $t p_{j}$, for those $j=8, \ldots, 12$ that have been selected to be produced.

Step 4. To allocate these remaining five operations to one of the cells, the nonlinear integer formulation Pl optimally allocates components so as to balance workloads. Notation is in Table 2.

(P1)

Minimize $X_{A 1}+X_{B 1}+X_{A 2}+X_{B 2}$

subject to 


$$
\begin{aligned}
& W_{1}+\sum_{j=8}^{12} t p_{j} X_{j}-X_{A 1}+X_{A 2}=W_{2 / 1}+\sum_{j=8}^{12} t p_{j}\left(1-X_{j}\right)-X_{B 1}+X_{B 2} \\
& \sum_{j=8}^{12} d_{j} X_{j}+s_{F 1}+\sum_{p=2}^{5}(-1)^{p+1} \sum_{\substack{\forall \bar{B} \subseteq B k \\
\exists|\overline{\bar{B}}|=p}} W_{\bar{B}} \prod_{j \subseteq}\left(X_{j} \cup \leq 1,3,6\right\} \\
& \sum_{j=8}^{12} d_{j}\left(1-X_{j}\right)+s_{F 21}+\sum_{p=2}^{5}(-1)^{p+1} \sum_{\substack{t \bar{B} \subseteq B k \\
\forall|\bar{B}|=p}} W_{\bar{B}} \prod_{j \subseteq \bar{B} \cup\{2,4,5,7\}}\left(1-X_{j}\right) \leq t_{B} \\
& X_{j}=0 \text { or } 1
\end{aligned}
$$

Problem P1 is a variation of the nonlinear integer formulation of the FMS loading problem of Stecke (1983).

There may be enough space in the tool magazines of each cell $(60 \times 2 \times 3=360$ slots) so that the two nonlinear tool magazine capacity constraints of Problem Pl may not be required. (This is currently the case, as can be seen from the data in the Appendix.) If so, then the problem is a (0-1) mixed integer program and can be solved quickly using any linear programming package, such as LINDO (see Schrage 1981).

Other linear formulations are possible. One (see Hwang 1986) is large and requires many constraints and variables. It needs a new variable to account for each cutting tool.

Alternatively, we suggest a heuristic based on LPT (longest processing time) rules to allocate operations to cells. This is similar to a first-fit decreasing rule, which performs well in some bin-packing problems. See, for example, Johnson (1973) and Stecke and Talbot (1985).

\section{Heuristic 2 for FMS cell loading (LPT)}

Step 1. Calculate $T P=\left(W_{1}+W_{2 / 1}+\Sigma_{j=8}^{12} t p_{j}\right) / 2=$ target workload for each cell to bal-

\begin{tabular}{|c|c|c|c|c|c|}
\hline \multicolumn{3}{|c|}{ Cell A } & \multicolumn{3}{|c|}{ Cell B } \\
\hline $\begin{array}{l}\text { Workload } \\
W_{A}\end{array}$ & $\begin{array}{l}\text { Slots } \\
s_{A}\end{array}$ & $\begin{array}{l}\text { Components } \\
\text { allocated } \\
C_{A}\end{array}$ & $\begin{array}{l}\text { Workload } \\
W_{B}\end{array}$ & $\begin{array}{l}\text { Slots } \\
s_{B}\end{array}$ & $\begin{array}{l}\text { Components } \\
\text { allocated } \\
C_{B}\end{array}$ \\
\hline$W_{1}$ & $s_{H 1}$ & $\subseteq\{1,3,6\}$ & $W_{2 / 1}$ & $s_{F / 1}$ & $\subseteq\{2,4,5,7\}$ \\
\hline
\end{tabular}
ance $=R W / 2$. Order the $t p_{j}$ according to LPT. For cell $\mathrm{A}$, initialize $W_{A}=W_{1}$, $s_{A}=s_{F}, C_{A}=\{\subseteq\{1,3,6\}\}$, and similarly for cell B, as in Table 3 .

Table 3. Cell allocation 
Step 2. Allocate each operation to a cell, in the LPT order, alternating each allocation. If tool magazine capacity is violated, reallocate components by swapping two adjacent in a pairwise interchange. Continue until tool magazine capacity is satisfied and all components have been allocated.

Balancing the workload on each cell is not always necessary. Sometimes it will be better to just find a feasible solution. A feasible allocation of componets to cells can be better than balancing because it is more flexible and allows more potential allocation options. Thus, more pooling or partial pooling can be done.

Balancing may be better because it may make it easier to handle a machine breakdown. Also, if the workloads on each cell are balanced, there may then be spare time at the end of the day to begin production of the next day's requirements for which the system is currently tooled.

However, this benefit may not materialize. Balancing allows less pooling or partial pooling, and the tool magazine capacity constraints of each machine or cell will be tighter. Hence, some of this spare time may be taken by changing tools (and perhaps fixture setup also). Another loading objective is to minimize the amount of tool changing from one day to the next.

The formulation Pl can be adapted to find a feasible rather than balanced solution. First, the first constraint that balances workload can be replaced by the following two constraints:

$$
\begin{aligned}
& W_{1}+\sum_{j=8}^{12} t p_{j} X_{j}-X_{A 1}+X_{A 2} \leq e(1440) m_{A} \\
& W_{211}+\sum_{j=8}^{12} t p_{j}\left(1-X_{j}\right)-X_{B 1}+X_{B 2} \leq e(1440) m_{B}
\end{aligned}
$$

In these constraints, $m_{A}\left(m_{B}\right)$ is the number of working machines in cell $A(B) . \mathrm{P} 2$ will still tend to balance workloads, since the objective function minimizes the overload and underload on each cell.

An objective function that does not aim to balance cell workloads and only finds a feasible solution can be developed by deleting the underload variables, $X_{A 1}$ and $X_{B 1}$, in the objective function and constraints as follows:

$$
\text { Minimize } X_{A 2}+X_{B 2}
$$

Each formulation (P1, P2, or P3) is appropriate at different times. The advantages to each approach have been discussed.

4.2.2. FMS machine loading. Within each cell, the components need to be allocated to one or more machine tools. A formulation similar to P1, P2, or P3 is appropriate. The tool 
magazine capacities need to be reduced, from that for cells (360) to that for machines (120). Similar and analogous new variables need to be defined.

The objective function is to maximize the number of component allocations to machines (up to three allocations per component). The constraints include tool magazine capacity and the maximum machine cutting time of $1440 \cdot e$ minutes per day per machine. Also, each of the selected components must be allocated to at least one machine, and preferably to two or three machines.

In addition to a suitable adaptation of algorithm 1 and heuristic 2, the following algorithm is also useful for both cell and machine loading. It combines the previous algorithms since it uses both P1 and LPT.

\section{Algorithm 3 for FMS machine loading}

Step 1. Solve a variation of the (0-1) linear program Pl by ignoring the tool magazine capacity constraints. The best possible balance is obtained. Order the components allocated to each machine (or cell) according to LPT.

Step 2. Is tool magazine capacity satisfied? If yes, go to step 4 . If no, go to step 3 .

Step 3. Tool magazine capacity is not satisfied. Interchange the component allocations of two adjacent components in the LPT sequence in reverse order. Update the parameters. Go to step 2.

Step 4. Will tool magazine capacities allow pooling or partial pooling? If yes, pool and duplicate operation assignments as much as possible. Then stop. If no, go to step 5.

Step 5. Examine pairwise interchanges of component allocations so as to maintain approximate cell workload balance (perfect balance is not necessary) and time constraints and to obtain a better tool magazine allocation with more pooling or partial pooling. Go to step 4.

Three algorithms and their variations have been proposed for cell and machine loading. In general, the appropriateness of each depends on the size of the problems solved, the amount of tool overlap, and the size and spare capacity of the computer used to solve these problems. The approach for the COMAU Torino FMS is discussed in the Appendix, after the detailed tooling data have been presented and analyzed.

Another consideration when allocating components to machines and when pooling machines is tool search time. It takes time to "search" for the next required cutter in a tool magazine. Searching does not mean looking for the tool. It is known where each tool is. Search time is the amount of time it takes for the magazine to rotate into position for the next required tool interchange. For FMSs that machine aluminum parts, the processing time per cutter may be very short for some cutters, i.e., one to three minutes. It can take longer for the magazine to rotate the next required cutter into position than for the current cutter to make its cut. 
Then the way cutters are placed in the magazines can be important. The more tools there are in a tool magazine, the longer the search time. For this reason, it may not always be desirable to fill each tool magazine.

Those cutters that are used a lot or wear relatively quickly may require duplicates (sisters) in the corresponding tool magazines. Duplicating tools can help to reduce the number of times that tools are changed but would also reduce the available tool magazine capacity. This is further addressed in the Appendix.

\subsection{Fixture allocation and usage}

Fixture types 2 and 4 require three and two setups, periodically, to hold different components. Fixture setup takes ten minutes per fixture, and only one fixture can be changed at a time.

At present, fixture setup does not appear to be a problem. As the daily requirements for one component type are near completion, visits to the fixture setup station can be phased, as it is free. A new component type that uses the same fixture type can be introduced slowly into the system. Production of these two component types will overlap for a short period of time.

The tool magazines will already be loaded with the correct cutters for both part types. Fixture setup should not warrant a tool setup. Occasionally, a few tools will need to be changed, both because of breakage and wearing and because the initial allocation may not have had room for all the tools that were required for the day. Fixture setup must be phased to minimize machine idle time (preferably none).

\subsection{FMS scheduling}

The FMS has been designed so that part input scheduling should be quite simple. As a part (component) is unloaded, any part of any part type that can use the particular fixture/ setup can be input until a component's day's requirements are (nearly) completed. (The "nearly" refers to those fixtures that require phased setups for new component types to be input into the system).

Since there is usually no tool setup between components (usually all tools have been loaded already), it does not matter which components are input next. Cutter breakage and wear may affect this slightly. Components will be machined in small batches dictated by the size of the raw material containers. As one container is filled, either the same or a different component container (for components that use the same fixture) can be brought out to the shop floor area around the FMS.

Not all of the component types can be on the shop floor for machining at the same time because of limited floor space and the sizes of the component containers. On the other hand, several component types do have to be available simultaneously so that both machines and fixtures of different fixture types are adequately utilized.

Containers of raw materials are brought to replace the finished components until the day's requirements, as dictated by the PTS/BSD algorithm, have been completed. Then, inventory to buffer the requirements of the following day or two can be produced. 


\subsection{Inventory policy}

Under normal conditions (no breakdowns, work stoppages, or unforeseen idle time occurrences), there should be some spare time at the end of each day to build up some inventory to buffer the following day's requirements. For each cell, only those components for which the cell is tooled can be machined, unless some tools are changed.

Usually the gearbox assembly schedule is firm for a week in advance. However, if the next day's orders are unknown, a component should be selected so that its inventory can be built up to the required batch size.

The main reason that some inventory should be carried is that there may not be enough capacity to meet production requirements. This could happen both in the case of a long breakdown or because of the daily mix changes.

The required workload $(R W)$ versus available capacity $(A W)$ over time is graphically described in Figure 2. The required workload is rather stable, with a 5-10 percent variation in the requirements of each gearbox type each day. The available workload is a step function of the number of up machines each day and the duration of the breakdowns.

We suggest several rules to guide this inventory buildup. For the spare time in each cell at the end of a day, the components of a gearbox that is required the next day should be machined. Each component should initially be selected such that its next-day requirements can be met with a high probability.

At the end of the day's production, there is some spare time, $S W_{A}$ and $S W_{B}$, the slack workload on cells A and B, respectively, in which to produce some inventory. Each cell is currently tooled to produce certain components. Let $r l_{i}$ be the requirements for gearbox $i$ for the next day and $r 2_{i}$ for the day after.

The components to produce for inventory are selected one at a time and initially, gearbox by gearbox. Select each gearbox $i$ such that all of the next day's requirements, $r l_{i}$, can likely be produced. If there is a choice, select a gearbox so that there are no requirements for it the day after $\left(r 2_{i}=0\right)$. If there is no such gearbox, the gearbox $i$ should be selected so that the total processing time requirements for all of its components are less than the slack time available on the cells and also use up the largest amount of the slack workload. In particular, the selected gearbox $i$ has

$$
\max _{j}\left\{r 1_{i} \cdot P_{i A(B)} \mid r 1_{i} \cdot P_{i A(B)} \leq S W_{A(B)}\right\}
$$

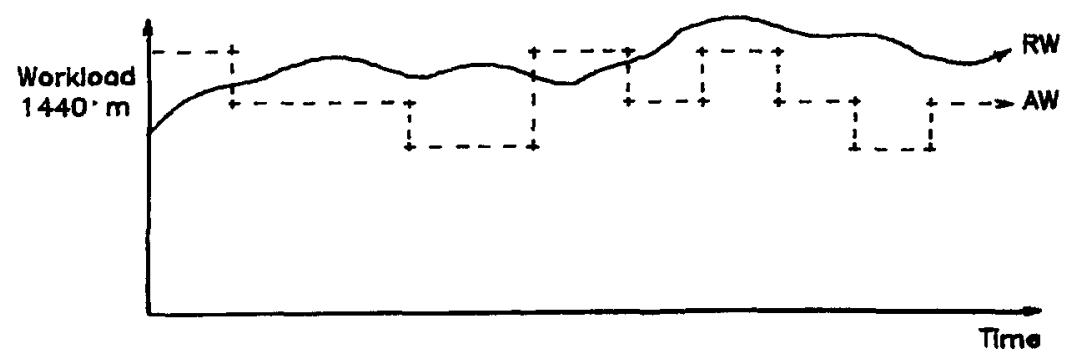

Figure 2. Required workload ( $R W$ ) versus available capacity ( $A W$ ). 
Continue to select gearboxes such that $r l_{i}$ can be produced. If time remains on only one of cell $\mathrm{A}$ or $\mathrm{B}$, try to fill the requirements for some component. The remaining time at the end of the day can be used to begin filling some other component's requirements.

If all the requirements for the next day are complete and there is still some remaining time, continue selecting gearboxes and components to produce the requirements for the day after, $r 2_{i}$. If the inventory includes all the following two days' requirements, the system should not produce further.

More than the next two days' inventory should not be produced unless the FMS has a breakdown of unknown duration. In this case, it is likely that the inventory will decrease rather than increase.

This FMS will not carry any safety stock to cover yield problems, unknown demand, or sudden new requirements. The only inventory will be of the actual requirements of the following day or two, in case of a random breakdown. Production is almost just-in-time, but a more accurate term is just-in-case (of breakdown).

\subsection{Implementation}

The planning and scheduling of the daily production should be performed every day midway through the third shift. If this planning day is called day $(n-1)$, it should be decided during the third shift of day $(n-1)$ what the requirements are for the FMS to produce for day $n$ that are needed for the gearbox assembly line on day $(n+1)$. Midway to end of third shift should allow time to place an order for tomorrow's raw materials and to acquire and change any cutters that are needed.

Midway through the second shift is when preliminary planning should be done for the day's inventory production. A little time will be necessary to place the internal order for the raw materials needed for the inventory production and also to order any cutters that might be required.

At times, one or more machine tools will be down for a long period, so that the FMS will not have enough capacity to meet the production requirements. Some of the production options include working the FMS for one or more shifts during the weekend or producing some components in a job shop. If the subsequent gearbox and truck assembly schedules can be changed, backlogs can be ordered.

For short breakdowns, it may be possible to continue production by just shifting some workload (and perhaps some tools) from one cell to another or from one machine to another. This is discussed in Section 5. Most of the data needed to perform such shifting are given in Table A9 of the Appendix. A complete description of how to use this information is provided there.

\section{Breakdown considerations}

In planning and scheduling the FMS, breakdowns need to be considered. On average, about an 80 percent system (all machines) utilization will be required from the FMS in order to meet the average daily production requirements. If all six gearbox types were to be produced 
every day, there would likely be problems if a machine or two broke down. First, it might be impossible to produce the requirements for all six gearbox types. Second, tool magazine reallocations and loadings might have to occur in order to continue to meet production as much as possible.

By producing fewer (say four or five) gearbox types each day, more pooling and partial pooling would be possible. Then if a machine were to go down, it might still be possible to continue production of these four or five gearboxes, although at a lower production rate. The reality of randomly occurring breakdowns was one of the reasons for defining precise inventory buildup and control policies in Section 4.5.

If much pooling has been done, then FMS production would continue. However, there may not be enough capacity on one of the cells. Workload can often be shifted from one cell to another. This may or may not require a shifting of tools. Information on tool slots required, tool overlap, and tool occupation by all combinations of components is contained in some of the tables of the Appendix. These can easily be used to make reallocation decisions as needed in real time to adapt to breakdowns.

\section{Future developments}

The FMS will work three shifts per day to meet the daily requirements for the components for the gearbox assembly line, which works two shifts per day. A future goal is to plan and schedule just-in-time, on a shift-by-shift basis rather than daily. Requirements will be given to the FMS for the next shift instead of for the next day.

This will result in inventory savings. However, we do not recommend that the FMS commence operation in just-in-time fashion. Instead, it is suggested that the procedures mentioned in Section 4 be used to plan and schedule production just-in-case. It takes months to bring an FMS up to full production, and there are many implementation problems, largely unforeseeable. The simpler methods that carry more inventory to cover uncertainty are recommended during plant startup.

In addition, new part types are likely to be introduced to be machined by the FMS in the future. New part types will constrain tool magazine capacity more than at present. This is another reason for using more general loading procedures than are necessary at present.

\section{Summary and conclusions}

This article completely describes a detailed case study of a COMAU-built Torino FMS, expected to be operational sometime in 1989 . The daily problems that need to be addressed to handle random breakdowns and daily mix changes are outlined. The main problem is a loading problem, and the complete tooling data and their analysis are provided in the Appendix.

The solutions that are provided here suggest a more flexible approach to operate the FMS successfully than the fixed solution of Table 1, which the vendor and user initially considered. Both daily workload changes and breakdowns would have rendered such a fixed allocation of operations to machines infeasible at times. 


\section{Appendix: Production and tooling data for purposes of pooling machines, allocating components, and loading cutters}

This Appendix contains some detailed supplementary information and data to support the algorithms provided in Section 4. In particular, the development and analysis of the detailed tooling data are presented here. Considering the data simplifies the loading problems. Sometimes the loading problems can be solved manually.

There are six families of similar components for the six gearbox types. There are 12 unique components. Often, the components are distinguished by the particular fixture and setup required. Information about these families is provided in Table A1.

The remaining tables provide tooling information, some of which is needed to use the algorithms of Section 4. In particular, Table A2 provides the basic tool data for each of the 12 unique components. Each tool is coded, and a star appears in the matrix whenever a certain tool is required to machine a particular component. Some of the tools take one slot in a magazine. The cutters whose labels begin with $\mathrm{T}$ take three slots.

Table Al. Families of parts

\begin{tabular}{llllll}
\hline $\begin{array}{l}\text { Component } \\
\text { types }\end{array}$ & Component description & $\begin{array}{l}\text { Initial } \\
\text { cell } \\
\text { allocation }\end{array}$ & $\begin{array}{l}\text { Fixture } \\
\text { type }\end{array}$ & Setup & $\begin{array}{l}\text { Gearbox } \\
\text { numbers }\end{array}$ \\
\hline 1 & Housing and front box (cover) & A & 1 & 1 & $1,2,3,4,5$ \\
2 & Half box rear (case) & B & 2 & 1 & $1,2,3$ \\
3 & Intermediate box & B & 2 & 2 & 4 \\
4 & Friction housing & A & 2 & 3 & 5,6 \\
5 & Half box clutch front & B & 3 & 1 & 6 \\
6 & Reduction half box rear & B & 4 & 1 & 6 \\
\hline
\end{tabular}

Table A2. Basic component/tool data

\begin{tabular}{|c|c|c|c|c|c|c|c|c|c|c|c|c|}
\hline \multirow[b]{2}{*}{ Tool } & \multicolumn{12}{|c|}{ Component } \\
\hline & 1 & 2 & 3 & 4 & 5 & 6 & 7 & 8 & 9 & 10 & 11 & 12 \\
\hline ADD01 & & & & & & & & & & & & - \\
\hline $\begin{array}{l}\text { ADD02 } \\
\text { AMD01 }\end{array}$ & $\bullet$ & & $\bullet$ & - & $\bullet$ & $\bullet$ & - & & & & & \\
\hline $\begin{array}{l}\text { AMD01 } \\
\text { AMD02 }\end{array}$ & & & & - & - & & - & & & • & & \\
\hline BAFOI & & & & & & & & & & . & & \\
\hline BAF02 & & & & & & & & & & • & & \\
\hline BAF03 & & & & & & & & & & • & & \\
\hline BAFO4 & & & & & & & & & - & & & \\
\hline BAF05 & $\bullet$ & & - & & & - & & & & & & \\
\hline BASOI & - & & $\bullet$ & & & - & & & & & & \\
\hline $\mathrm{BASO} 2$ & & & & & & & & & - & & & \\
\hline BASO3 & & & & & & & & & & & & - \\
\hline BASO4 & & & & & & & - & & & • & & \\
\hline BAS05 & & & & & & & & & • & & & \\
\hline BAS06 & & & & - & • & & & & & & & \\
\hline
\end{tabular}


Table A2. Basic component/tool data (continued)

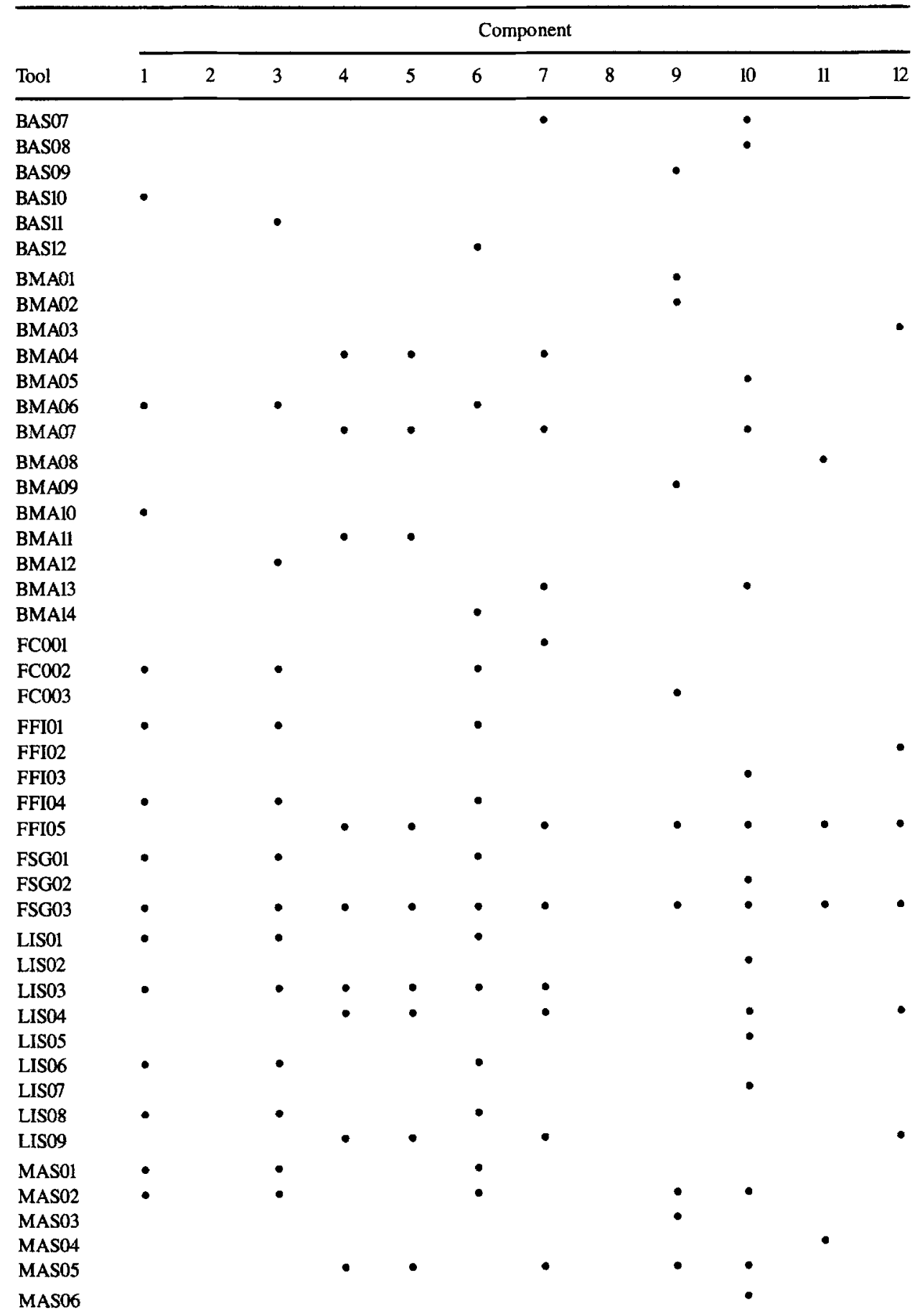


Table A2. Basic component/tool data (continued)

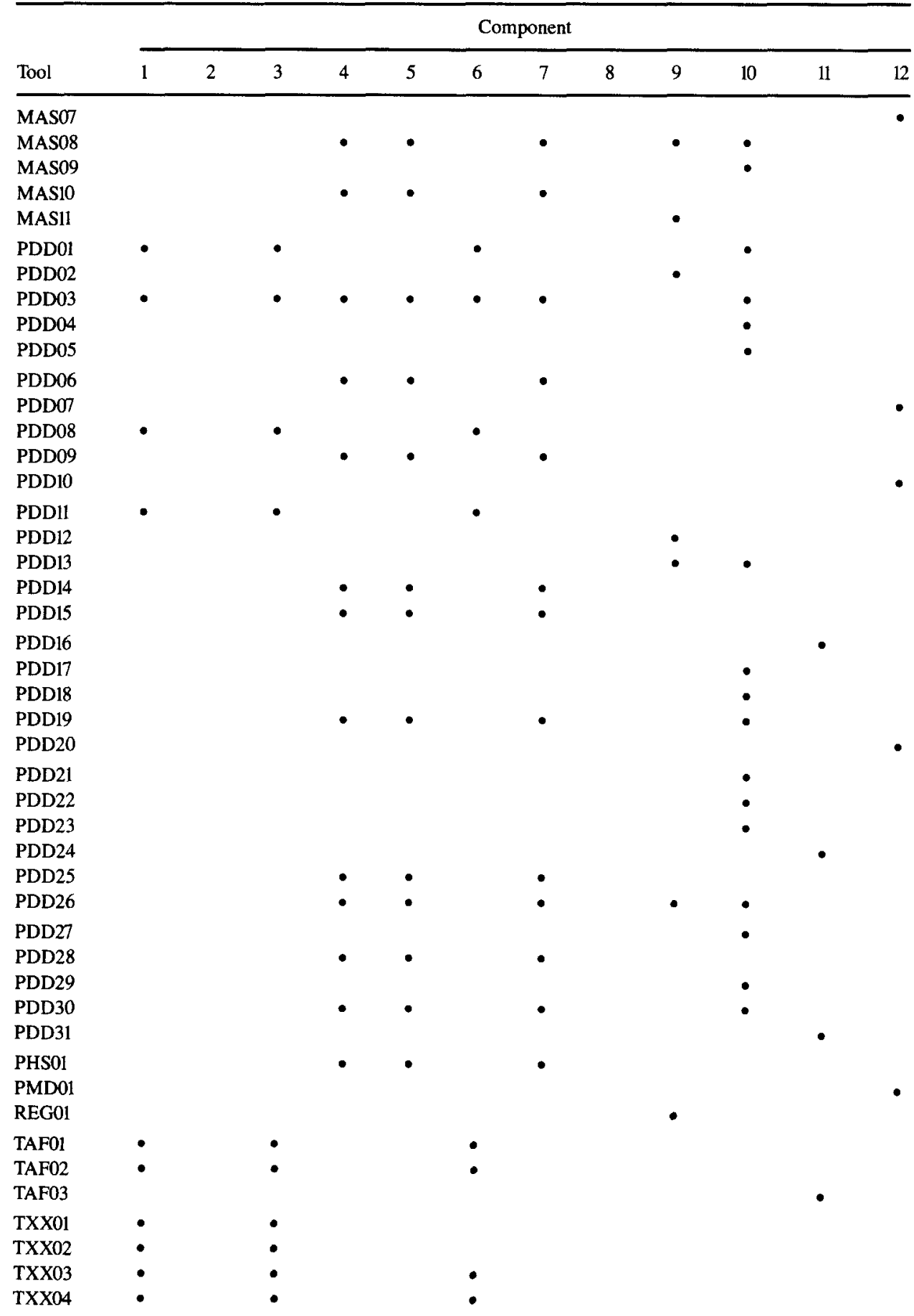


Table A2. Basic component/tool data (continued)

\begin{tabular}{|c|c|c|c|c|c|c|c|c|c|c|c|c|}
\hline \multirow[b]{2}{*}{ Tool } & \multicolumn{12}{|c|}{ Component } \\
\hline & 1 & 2 & 3 & 4 & 5 & 6 & 7 & 8 & 9 & 10 & 11 & 12 \\
\hline TXX05 & - & & $\bullet$ & & & & & & & & & \\
\hline TXX06 & - & & - & & & & & & & & & \\
\hline TXXO7 & - & & $\bullet$ & & & $\bullet$ & & & & & & \\
\hline TXX08 & & & & & & - & & & & & & \\
\hline TXX09 & & & & & & • & & & & & & \\
\hline TXX10 & & & & & & $\bullet$ & & & & & & \\
\hline TXX11 & & & & & & - & & & & & & \\
\hline TXX12 & & & & - & - & & - & & & - & & \\
\hline TXX13 & & & & - & - & & - & & & $\bullet$ & & \\
\hline TXX14 & & & & $\bullet$ & - & & - & & & - & & \\
\hline TXX15 & & & & & & & - & & & & & \\
\hline TXX16 & & & & - & - & & - & & - & & & \\
\hline TXX17 & & & & • & - & & - & & & $\bullet$ & & \\
\hline TXX18 & & & & - & $\bullet$ & & - & & & $\bullet$ & & \\
\hline TXX19 & & & & - & - & & - & & & $\bullet$ & & \\
\hline TXX20 & & & & & & & - & & & & & \\
\hline TXX21 & & & & - & - & & - & & - & & & - \\
\hline TXX22 & & & & • & - & & & & & & & \\
\hline $\mathrm{TXX} 23$ & & & & $\bullet$ & - & & & & & & & \\
\hline $\mathrm{TXX} 24$ & & & & & & & & & & & $\bullet$ & \\
\hline TXX25 & & & & & & & & & & & $\bullet$ & \\
\hline TXX26 & & & & & & & & & & • & & \\
\hline TXX27 & & & & & & & & & & $\bullet$ & & \\
\hline TXX28 & & & & & & & & & & $\bullet$ & & \\
\hline TXX29 & & & & & & & & & & $\bullet$ & & \\
\hline TXX30 & & & & & & & & & & $\bullet$ & & \\
\hline TXX31 & & & & & & & & & & • & & \\
\hline TXX32 & & & & & & & & & & & & - \\
\hline TXX33 & & & & & & & & & & & & - \\
\hline TXX34 & & & & & & & & & & & & - \\
\hline TXX35 & & & & & & & & & • & & & \\
\hline TXX36 & & & & & & & & & • & & & \\
\hline TXX37 & & & & & & & & & • & & & \\
\hline TXX38 & & & & & & & & & $\bullet$ & & & \\
\hline,,,,, & & & & & & & & • & & & & \\
\hline$\cdots$ & & - & & & & & & & & & & \\
\hline
\end{tabular}

At this point, there are no tool data available for components 2 and 8. Space for these is indicated in the last two starred entries of Table A2. When these data become available, the entries in the matrix of Table A2 can be updated. The new tools required for these components can be added to the list. In addition, the current tooling data of Table A2 may be revised. As new data are received, some of the insights, information, and recommendations in the remainder of this Appendix may change. This is why the suggested solution approaches of Section 4 are general. Future changes and updates can then be accommodated. 
The purpose of compiling the information in the format of Table A2 was to identify components that seem to share many of the same tools. This insight is difficult to get by scanning lists of tools. From Table A2, it can be seen that components 1,3 , and 6 seem to share many common tools. Similarly, components 4,5 , and 7 seem to share many tools. In addition, component 2 is known to be similar to components 4,5 , and 7 . Component 8 is similar to component 10 .

Although the similarities with respect to tool sharing can be observed in Table.A2 about some of the components, information about the other components cannot yet be observed. For this reason, several of the columns of Table A2 are interchanged in order to cluster similar components together. The results are those in Table A3, where components 1,3 , and 6 are clustered together. Also, components 2, 4, 5, and 7 are adjacent. Finally, components 8 and 10 are clustered, although there are no data as yet for component 8 .

Table A3. Columns (components) interchanged to see tool commonality

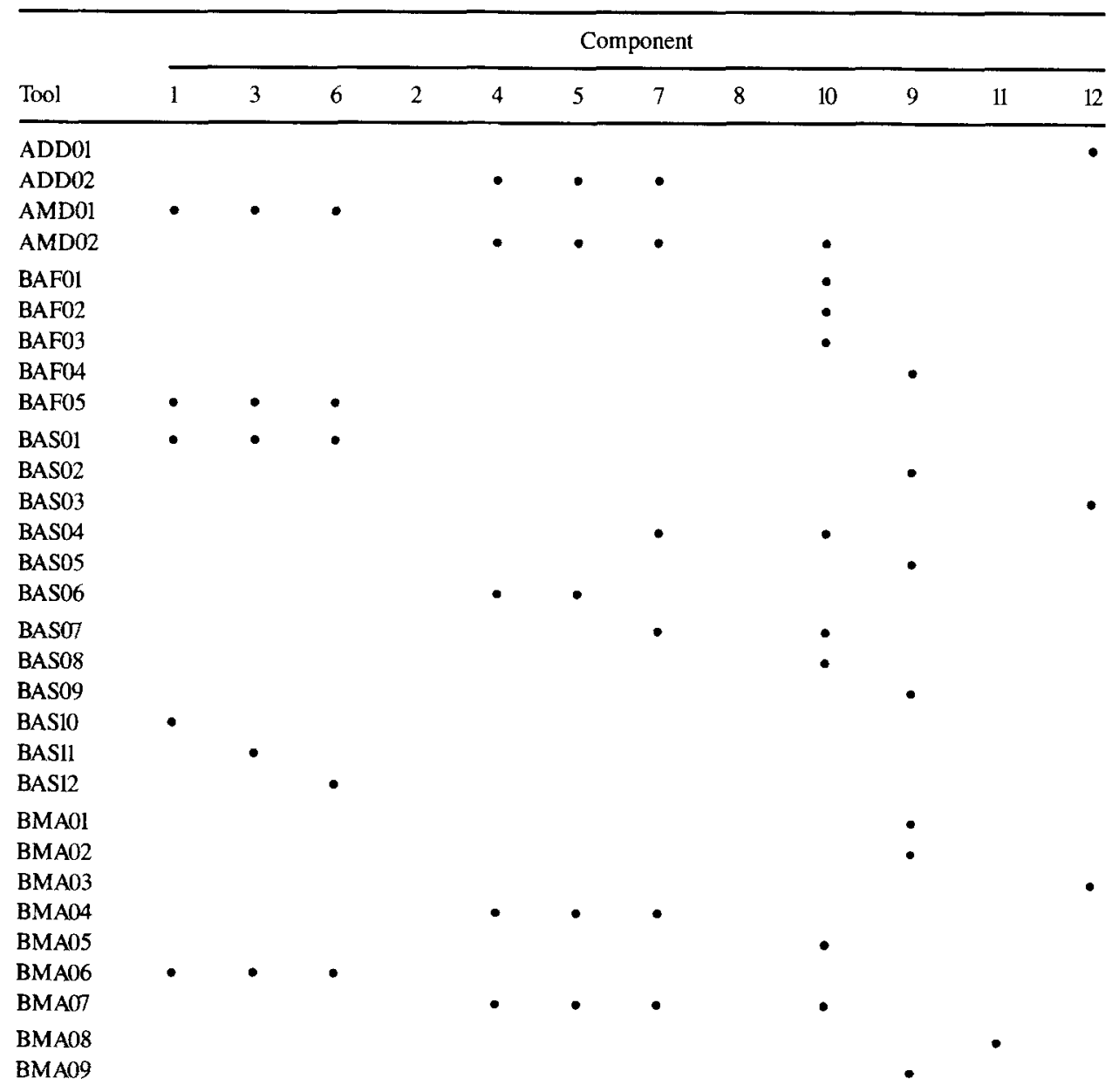


Table A3. Columns (components) interchanged to see tool commonality (continued)

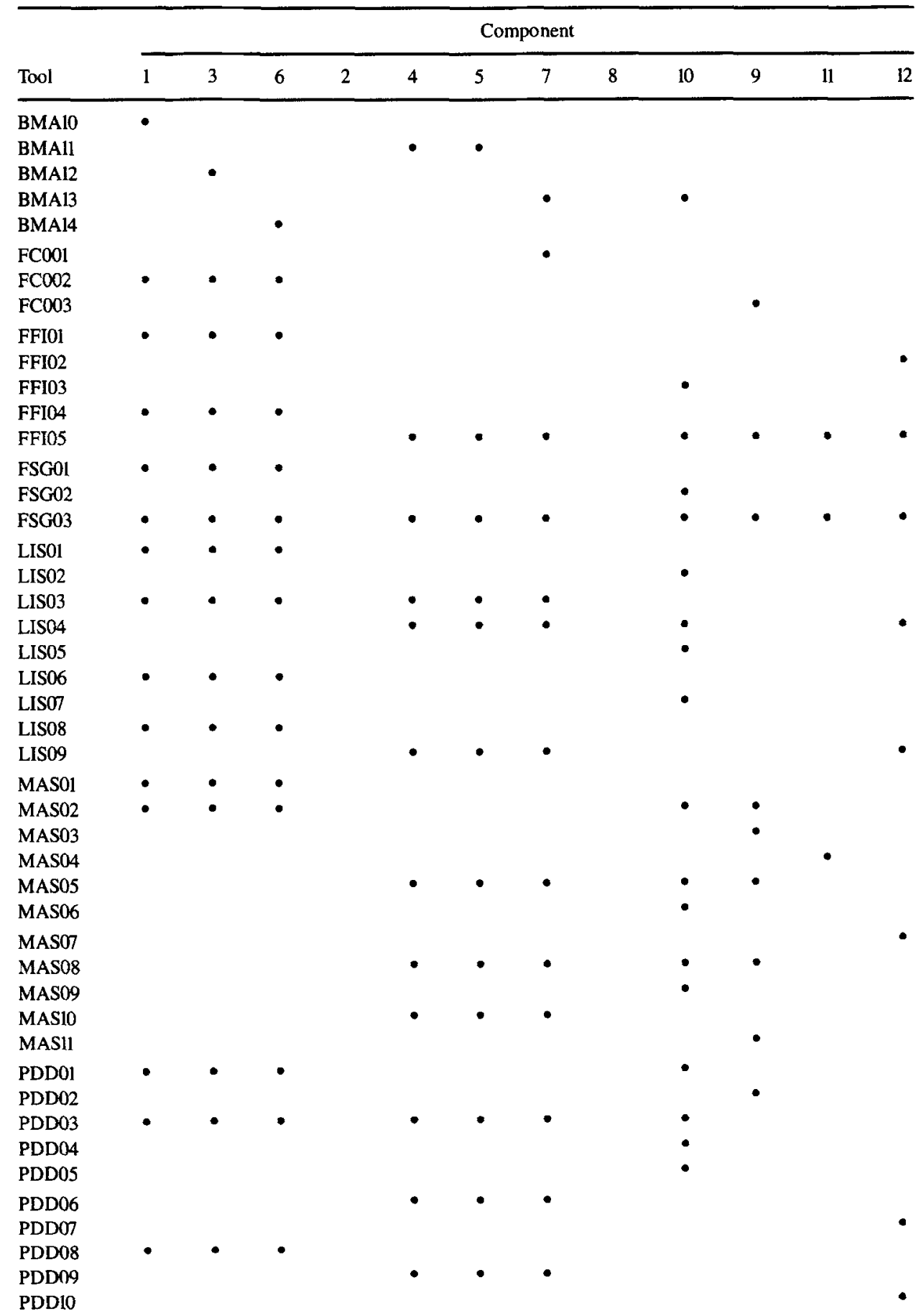


Table A3. Columns (components) interchanged to see tool commonality (continued)

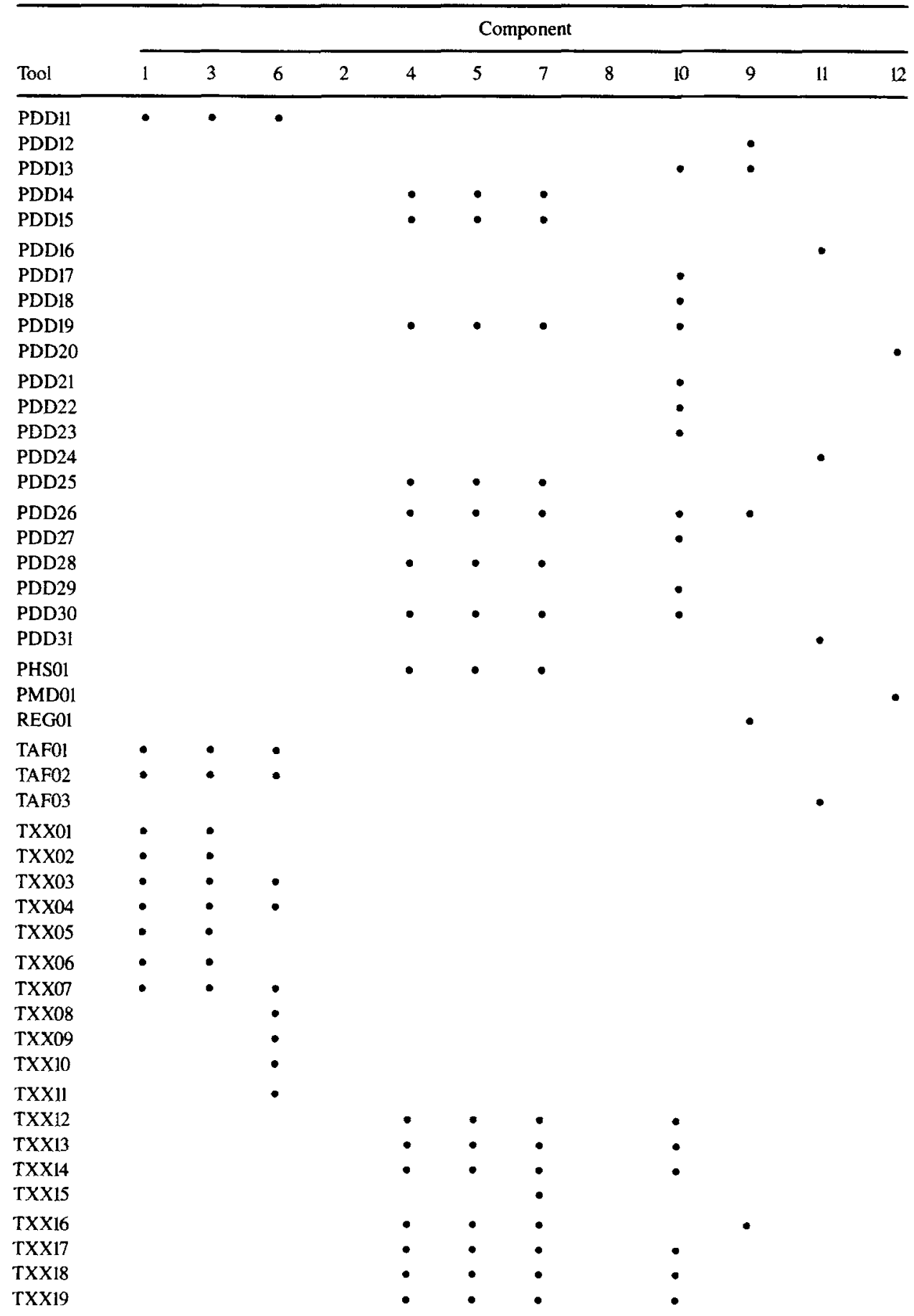


Table A3. Columns (components) interchanged to see tool commonality (continued)

\begin{tabular}{|c|c|c|c|c|c|c|c|c|c|c|c|c|}
\hline \multirow[b]{2}{*}{ Tool } & \multicolumn{12}{|c|}{ Component } \\
\hline & 1 & 3 & 6 & 2 & 4 & 5 & 7 & 8 & 10 & 9 & 11 & 12 \\
\hline$T \times \times 20$ & & & & & & & - & & & & & \\
\hline $\mathrm{TXX21}$ & & & & & - & - & - & & & - & & - \\
\hline TXX22 & & & & & • & - & & & & & & \\
\hline $\mathrm{TXX23}$ & & & & & - & - & & & & & & \\
\hline TXX24 & & & & & & & & & & & - & \\
\hline $\mathrm{TXX25}$ & & & & & & & & & & & - & \\
\hline TXX26 & & & & & & & & & - & & & \\
\hline $\mathrm{TXX27}$ & & & & & & & & & - & & & \\
\hline TXX28 & & & & & & & & & $\bullet$ & & & \\
\hline TXX29 & & & & & & & & & - & & & \\
\hline TXX30 & & & & & & & & & • & & & \\
\hline TXX31 & & & & & & & & & • & & & \\
\hline TXX32 & & & & & & & & & & & & - \\
\hline TXX33 & & & & & & & & & & & & - \\
\hline TXX34 & & & & & & & & & & & & - \\
\hline TXX35 & & & & & & & & & & - & & \\
\hline TXX36 & & & & & & & & & & - & & \\
\hline TXX37 & & & & & & & & & & - & & \\
\hline TXX38 & & & & & & & & & & - & & \\
\hline,$\ldots$ & & & & & & & & $\bullet$ & & & & \\
\hline$\ldots \ldots$ & & & & - & & & & & & & & \\
\hline
\end{tabular}

Next, the rows of Table $A 3$ are interchanged in order to complete the clustering. First, all tools required by components 1,3 , and 6 are moved together. Also, all tools of components 2, 4, 5, and 7 are adjacent. This allows both the common and unique tools of the remaining five components, $8,9,10,11$, and 12 , to be identified and clustered. The results of interchanging the rows (tools) are provided in Tables A4 and A5. Since the clustering is not unique, two different views of this clustering are presented.

Tables A4 and A5 provide two different views of the clusters and shared tools. This clustering information was used in Section 4 to help determine the appropriate algorithms to load the cells and machines. For example, the clusters show that components 1,3 , and 6 are similar. All require fixture 1 . These should be allocated to the same cell and machines.

Table A4. Rows (tools) interchanged to cluster components having common tools

\begin{tabular}{|c|c|c|c|c|c|c|c|c|c|c|c|c|}
\hline \multirow[b]{2}{*}{ Tool } & \multicolumn{12}{|c|}{ Component } \\
\hline & 1 & 3 & 6 & 2 & 4 & 5 & 7 & 8 & 10 & 9 & 11 & 12 \\
\hline AMD01 & - & $\bullet$ & $\bullet$ & & & & & & & & & \\
\hline BAF05 & $\bullet$ & - & $\bullet$ & & & & & & & & & \\
\hline BASO1 & $\bullet$ & $\bullet$ & - & & & & & & & & & \\
\hline BMA06 & - & $\bullet$ & - & & & & & & & & & \\
\hline $\mathrm{FCOO} 2$ & $\bullet$ & $\bullet$ & $\bullet$ & & & & & & & & & \\
\hline
\end{tabular}


Table A4. Rows (tools) interchanged to cluster components having common tools (continued)

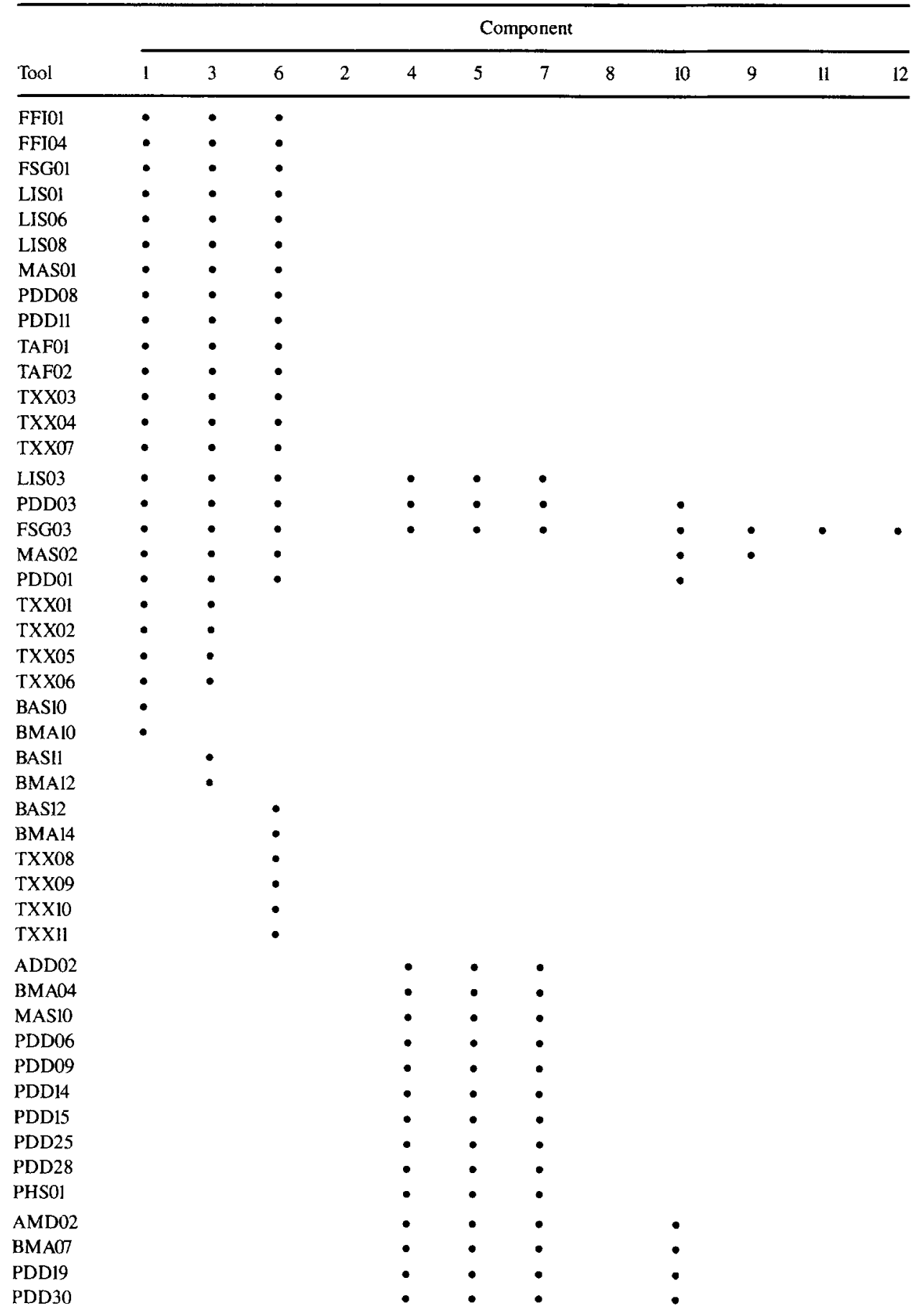


Table A4. Rows (tools) interchanged to cluster components having common tools (continued)

\begin{tabular}{|c|c|c|c|c|c|c|c|c|c|c|c|c|}
\hline \multirow[b]{2}{*}{ Tool } & \multicolumn{12}{|c|}{ Component } \\
\hline & 1 & 3 & 6 & 2 & 4 & 5 & 7 & 8 & 10 & 9 & 11 & 12 \\
\hline TXX12 & & & & & $\bullet$ & $\bullet$ & $\bullet$ & & $\bullet$ & & & \\
\hline TXX13 & & & & & - & $\bullet$ & $\bullet$ & & $\bullet$ & & & \\
\hline TXX14 & & & & & $\bullet$ & $\bullet$ & $\bullet$ & & $\bullet$ & & & \\
\hline TXXI7 & & & & & $\bullet$ & $\bullet$ & $\bullet$ & & $\bullet$ & & & \\
\hline TXX18 & & & & & $\bullet$ & $\bullet$ & $\bullet$ & & $\bullet$ & & & \\
\hline TXX19 & & & & & $\bullet$ & $\bullet$ & $\bullet$ & & $\bullet$ & & & \\
\hline TXX16 & & & & & $\bullet$ & $\bullet$ & $\bullet$ & & & $\bullet$ & & \\
\hline LIS09 & & & & & $\bullet$ & - & - & & & & & $\bullet$ \\
\hline MASO5 & & & & & $\bullet$ & $\bullet$ & $\bullet$ & & $\bullet$ & - & & \\
\hline MASO8 & & & & & $\bullet$ & $\bullet$ & $\bullet$ & & $\bullet$ & - & & \\
\hline PDD26 & & & & & $\bullet$ & $\bullet$ & $\bullet$ & & • & $\bullet$ & & \\
\hline LISO4 & & & & & $\bullet$ & - & $\bullet$ & & $\bullet$ & & & - \\
\hline TXX21 & & & & & $\bullet$ & $\bullet$ & $\bullet$ & & & $\bullet$ & & $\bullet$ \\
\hline FFI05 & & & & & $\bullet$ & $\bullet$ & $\bullet$ & & $\bullet$ & $\bullet$ & - & $\bullet$ \\
\hline BAS06 & & & & & $\bullet$ & - & & & & & & \\
\hline BMAll & & & & & $\bullet$ & $\bullet$ & & & & & & \\
\hline $\mathrm{TXX} 22$ & & & & & - & - & & & & & & \\
\hline $\mathrm{TXX23}$ & & & & & $\bullet$ & $\bullet$ & & & & & & \\
\hline BASO4 & & & & & & & $\bullet$ & & $\bullet$ & & & \\
\hline BASO7 & & & & & & & $\bullet$ & & $\bullet$ & & & \\
\hline BMA13 & & & & & & & $\bullet$ & & $\bullet$ & & & \\
\hline $\mathrm{FCOO1}$ & & & & & & & $\bullet$ & & & & & \\
\hline TXX15 & & & & & & & $\bullet$ & & & & & \\
\hline TXX20 & & & & & & & $\bullet$ & & & & & \\
\hline BAF01 & & & & & & & & & $\bullet$ & & & \\
\hline BAF02 & & & & & & & & & $\bullet$ & & & \\
\hline BAF03 & & & & & & & & & • & & & \\
\hline BAS08 & & & & & & & & & - & & & \\
\hline BMA05 & & & & & & & & & $\bullet$ & & & \\
\hline FFl03 & & & & & & & & & - & & & \\
\hline FSG02 & & & & & & & & & $\bullet$ & & & \\
\hline LISO2 & & & & & & & & & $\bullet$ & & & \\
\hline LISO5 & & & & & & & & & $\bullet$ & & & \\
\hline LISO7 & & & & & & & & & $\bullet$ & & & \\
\hline MAS06 & & & & & & & & & $\bullet$ & & & \\
\hline MASO9 & & & & & & & & & $\bullet$ & & & \\
\hline PDD04 & & & & & & & & & - & & & \\
\hline PDD05 & & & & & & & & & $\bullet$ & & & \\
\hline PDD17 & & & & & & & & & $\bullet$ & & & \\
\hline PDD18 & & & & & & & & & $\bullet$ & & & \\
\hline PDD21 & & & & & & & & & $\bullet$ & & & \\
\hline PDD22 & & & & & & & & & - & & & \\
\hline PDD23 & & & & & & & & & - & & & \\
\hline PDD27 & & & & & & & & & $\bullet$ & & & \\
\hline PDD29 & & & & & & & & & $\bullet$ & & & \\
\hline TXX26 & & & & & & & & & $\bullet$ & & & \\
\hline
\end{tabular}


Table A4. Rows (tools) interchanged to cluster components having common tools (continued)

\begin{tabular}{|c|c|c|c|c|c|c|c|c|c|c|c|c|}
\hline \multirow[b]{2}{*}{ Tool } & \multicolumn{12}{|c|}{ Component } \\
\hline & 1 & 3 & 6 & 2 & 4 & 5 & 7 & 8 & 10 & 9 & 11 & 12 \\
\hline $\mathrm{T} \times \mathrm{X} 27$ & & & & & & & & & $\bullet$ & & & \\
\hline TXX28 & & & & & & & & & $\bullet$ & & & \\
\hline TXX29 & & & & & & & & & $\bullet$ & & & \\
\hline TXX30 & & & & & & & & & $\bullet$ & & & \\
\hline TXX31 & & & & & & & & & $\bullet$ & & & \\
\hline PDDI3 & & & & & & & & & $\bullet$ & - & & \\
\hline BAF04 & & & & & & & & & & • & & \\
\hline $\mathrm{BAS} 02$ & & & & & & & & & & - & & \\
\hline BASO5 & & & & & & & & & & $\bullet$ & & \\
\hline BAS09 & & & & & & & & & & $\bullet$ & & \\
\hline BMA01 & & & & & & & & & & - & & \\
\hline $\mathrm{BMA02}$ & & & & & & & & & & $\bullet$ & & \\
\hline BMA09 & & & & & & & & & & $\bullet$ & & \\
\hline $\mathrm{FCOO3}$ & & & & & & & & & & $\bullet$ & & \\
\hline MASO3 & & & & & & & & & & - & & \\
\hline MAS11 & & & & & & & & & & $\bullet$ & & \\
\hline PAD02 & & & & & & & & & & $\bullet$ & & \\
\hline PDD12 & & & & & & & & & & $\bullet$ & & \\
\hline REG01 & & & & & & & & & & $\bullet$ & & \\
\hline TXX35 & & & & & & & & & & $\bullet$ & & \\
\hline TXX36 & & & & & & & & & & $\bullet$ & & \\
\hline TXX37 & & & & & & & & & & $\bullet$ & & \\
\hline TXX38 & & & & & & & & & & $\bullet$ & & \\
\hline BMA08 & & & & & & & & & & & $\bullet$ & \\
\hline MAS04 & & & & & & & & & & & - & \\
\hline PDD16 & & & & & & & & & & & $\bullet$ & \\
\hline PDD24 & & & & & & & & & & & $\bullet$ & \\
\hline PDD31 & & & & & & & & & & & $\bullet$ & \\
\hline TAF03 & & & & & & & & & & & • & \\
\hline $\mathrm{TXX} 24$ & & & & & & & & & & & $\bullet$ & \\
\hline TXX25 & & & & & & & & & & & $\bullet$ & \\
\hline ADDO1 & & & & & & & & & & & & $\bullet$ \\
\hline BASO3 & & & & & & & & & & & & - \\
\hline BMA03 & & & & & & & & & & & & $\bullet$ \\
\hline FFI02 & & & & & & & & & & & & $\bullet$ \\
\hline MASO7 & & & & & & & & & & & & $\bullet$ \\
\hline PDD07 & & & & & & & & & & & & - \\
\hline PDD10 & & & & & & & & & & & & $\bullet$ \\
\hline PDD20 & & & & & & & & & & & & $\bullet$ \\
\hline PMDOI & & & & & & & & & & & & $\bullet$ \\
\hline TXX32 & & & & & & & & & & & & $\bullet$ \\
\hline TXX33 & & & & & & & & & & & & $\bullet$ \\
\hline TXX34 & & & & & & & & & & & & $\bullet$ \\
\hline,,,, & & & & & & & & $\bullet$ & & & & \\
\hline$\ldots$ & & & & $\bullet$ & & & & & & & & \\
\hline
\end{tabular}


Table A5. Another component/tool clustering

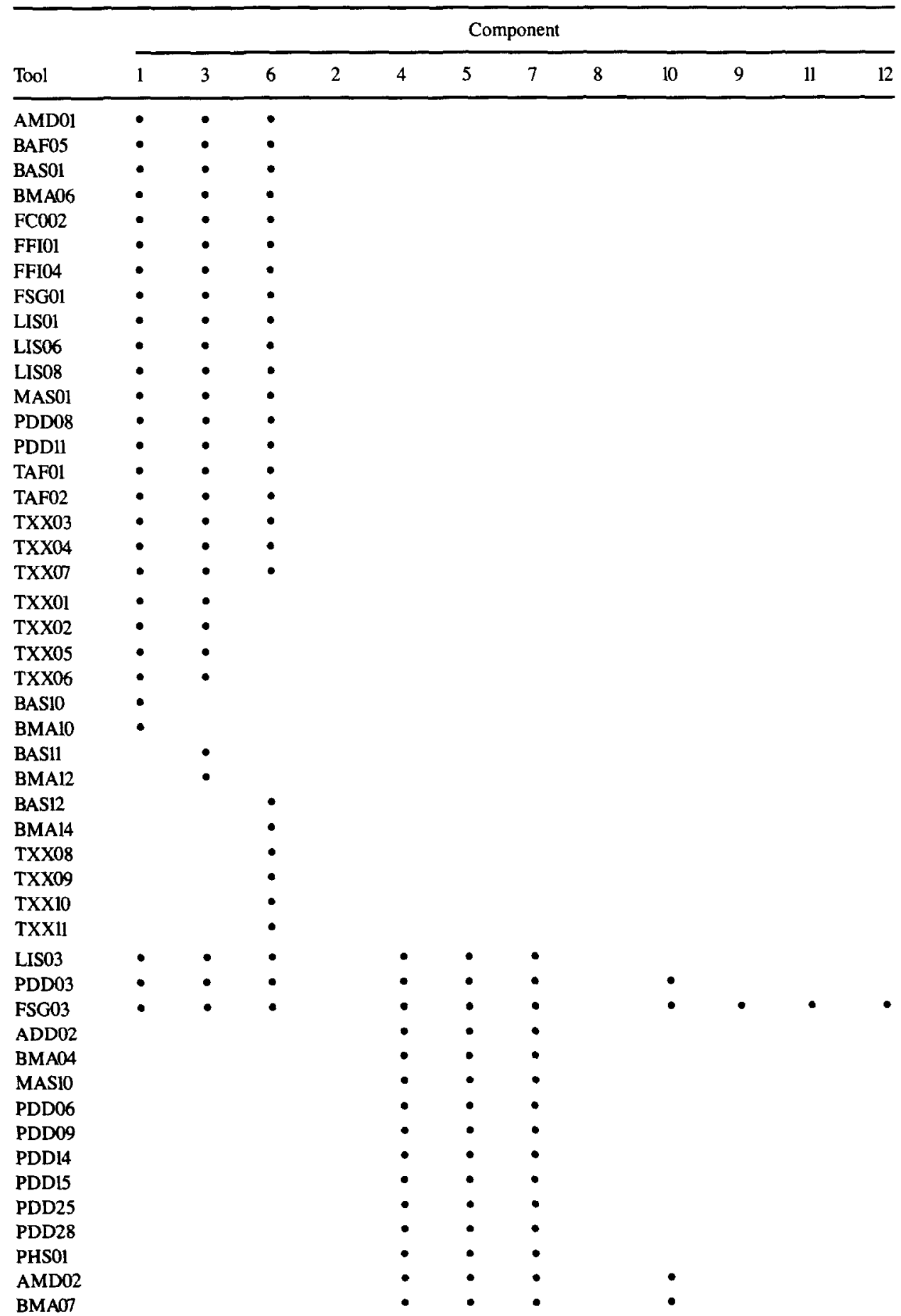


Table A5. Another component/tool clustering (continued)

\begin{tabular}{|c|c|c|c|c|c|c|c|c|c|c|c|c|}
\hline \multirow[b]{2}{*}{ Tool } & \multicolumn{12}{|c|}{ Component } \\
\hline & 1 & 3 & 6 & 2 & 4 & 5 & 7 & 8 & 10 & 9 & 11 & 12 \\
\hline PDDI9 & & & & & $\bullet$ & $\bullet$ & $\bullet$ & & $\bullet$ & & & \\
\hline PDD30 & & & & & - & $\bullet$ & - & & • & & & \\
\hline TXX12 & & & & & $\bullet$ & - & - & & $\bullet$ & & & \\
\hline TXX13 & & & & & $\bullet$ & - & - & & $\bullet$ & & & \\
\hline TXX14 & & & & & $\bullet$ & $\bullet$ & - & & $\bullet$ & & & \\
\hline TXX17 & & & & & - & $\bullet$ & - & & $\bullet$ & & & \\
\hline TXX18 & & & & & - & $\bullet$ & $\bullet$ & & - & & & \\
\hline TXX19 & & & & & $\bullet$ & $\bullet$ & $\bullet$ & & $\bullet$ & & & \\
\hline MASOS & & & & & $\bullet$ & $\bullet$ & $\bullet$ & & • & $\bullet$ & & \\
\hline MAS08 & & & & & $\bullet$ & $\bullet$ & - & & $\bullet$ & - & & \\
\hline PDD26 & & & & & - & $\bullet$ & $\bullet$ & & $\bullet$ & $\bullet$ & & \\
\hline LISO4 & & & & & $\bullet$ & - & $\bullet$ & & $\bullet$ & & & $\bullet$ \\
\hline TXX21 & & & & & - & $\bullet$ & $\bullet$ & & & $\bullet$ & & - \\
\hline FFI05 & & & & & - & $\bullet$ & - & & - & $\bullet$ & $\bullet$ & - \\
\hline BAS06 & & & & & - & - & & & & & & \\
\hline BMAll & & & & & $\bullet$ & $\bullet$ & & & & & & \\
\hline TXX22 & & & & & $\bullet$ & $\bullet$ & & & & & & \\
\hline $\mathrm{TXX} 23$ & & & & & $\bullet$ & $\bullet$ & & & & & & \\
\hline $\mathrm{FCOO1}$ & & & & & & & $\bullet$ & & & & & \\
\hline TXX15 & & & & & & & $\bullet$ & & & & & \\
\hline $\mathrm{T} \times \times 20$ & & & & & & & $\bullet$ & & & & & \\
\hline BAS04 & & & & & & & $\bullet$ & & $\bullet$ & & & \\
\hline BASO7 & & & & & & & $\bullet$ & & $\bullet$ & & & \\
\hline BMAI3 & & & & & & & $\bullet$ & & $\bullet$ & & & \\
\hline MASO2 & $\bullet$ & $\bullet$ & $\bullet$ & & & & & & - & • & & \\
\hline PDD01 & $\bullet$ & $\bullet$ & $\bullet$ & & & & & & $\bullet$ & & & \\
\hline BAF01 & & & & & & & & & $\bullet$ & & & \\
\hline $\mathrm{BAF02}$ & & & & & & & & & - & & & \\
\hline $\mathrm{BAF} 03$ & & & & & & & & & $\bullet$ & & & \\
\hline BASO8 & & & & & & & & & - & & & \\
\hline BMA05 & & & & & & & & & $\bullet$ & & & \\
\hline FFI03 & & & & & & & & & - & & & \\
\hline $\mathrm{FSGO} 2$ & & & & & & & & & $\bullet$ & & & \\
\hline LISO2 & & & & & & & & & $\bullet$ & & & \\
\hline LIS05 & & & & & & & & & - & & & \\
\hline LISO7 & & & & & & & & & - & & & \\
\hline MAS06 & & & & & & & & & - & & & \\
\hline MAS09 & & & & & & & & & - & & & \\
\hline PDD04 & & & & & & & & & $\bullet$ & & & \\
\hline PDD05 & & & & & & & & & - & & & \\
\hline PDD17 & & & & & & & & & - & & & \\
\hline PDD18 & & & & & & & & & - & & & \\
\hline PDD21 & & & & & & & & & $\bullet$ & & & \\
\hline PDD22 & & & & & & & & & $\bullet$ & & & \\
\hline PDD23 & & & & & & & & & $\bullet$ & & & \\
\hline $\operatorname{PDD} 27$ & & & & & & & & & - & & & \\
\hline PDD29 & & & & & & & & & $\bullet$ & & & \\
\hline TXX26 & & & & & & & & & $\bullet$ & & & \\
\hline
\end{tabular}


Table A5. Another component/tool clustering (continued)

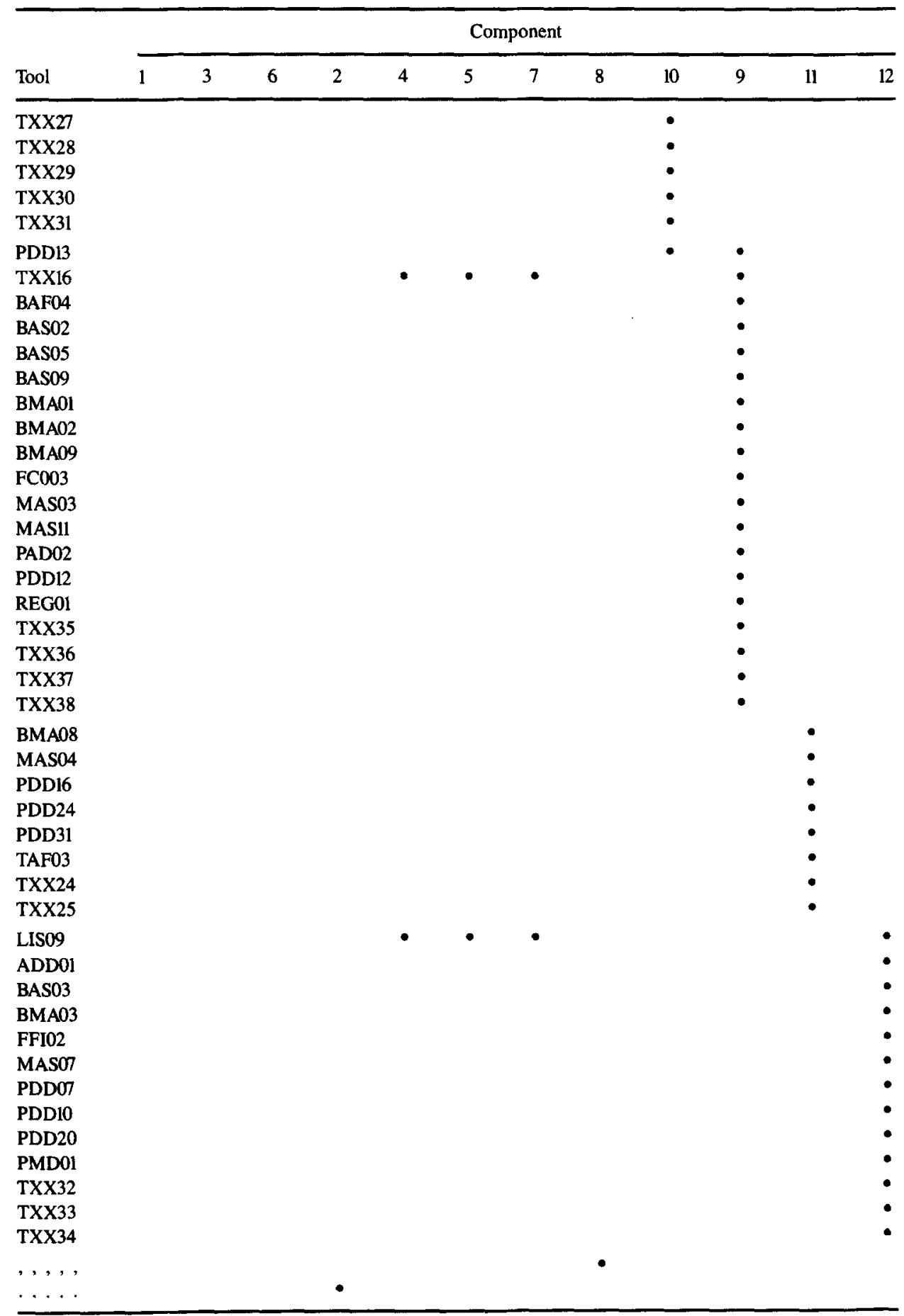


Table AG Number of tool magazine slots and tools required by each component

\begin{tabular}{lcc}
\hline Component & Slots & Tools \\
\hline 1 & 48 & 30 \\
2 & $*$ & + \\
3 & 48 & 30 \\
4 & 55 & 35 \\
5 & 55 & 35 \\
6 & 48 & 30 \\
7 & 57 & 37 \\
8 & $*$ & + \\
9 & 38 & 26 \\
10 & 74 & 50 \\
11 & 16 & 10 \\
12 & 25 & 17 \\
\hline
\end{tabular}

The remaining tables provide the actual tooling data that need to be input into the models and algorithms of Section 4. For example, Table A6 gives the number of tools and the tool slots required by each component. The number of tool slots is the necessary information for component allocation purposes. The additional information on the number of tools will only be useful for estimating the time to change cutters and will not be used again until either simulation or system operation.

Table A6 provides the tooling data for the individual components. However, there is a large amount of tool sharing among several components. The clustering tables demonstrate this. Not included in this article is a large computer output that provides, for each of all possible combinations of components that may be allocated together to the same cell or machine, the following information:

The number of tools required and tool slots occupied by the particular combination.

The number of unique tools and tool slots required only by each component of the particular combination.

The number of tools in common required by all of the components of the particular combination.

We will call this large program "all combinations" when we need to refer to some of the detailed information in it. Table A9 demonstrates a small and useful subset of the entire information contained in "all combinations."

From the clustering and "all combinations" information, it can be seen that it is reasonable for components 1,3 , and 6 (now renamed as combination number 1 ) to always be allocated to the same cell (A) or machine because there is such a high duplication of cutters in common. Similarly, components 2, 4, 5, and 7 are renamed combination number 2 and will always be assigned to the other cell (B). This clustering of similar components greatly reduces the amount of information required by a manager trying to operate the FMS effectively. The original 12 components can now be reduced to the following six: 


\begin{tabular}{ll}
\hline Old components & New numbering \\
\hline$\{1,3,6\}$ & 1 \\
$\{2,4,5,7\}$ & 2 \\
9 & 3 \\
$\{8,10\}$ & 4 \\
11 & 5 \\
12 & 6 \\
\hline
\end{tabular}

Table A7 is analogous to Table A6 for the six new sets of clustered components.

Finally, Tables A8 and A9 contain the tooling information for all possible combinations of the renumbered clusters. This is a significant reduction in the total number of combinations.

The first columns of Tables A8 and A9 list the components in a particular combination. There are two to six components in each combination. The next column (labeled "tools/slots") provides the number of tools and slots taken by the particular combination. The next columns give the number of slots taken by unique tools specific to each component cluster in the particular combination. The final column provides the number of tools and slots taken by tools that are common to all the component clusters in the particular combination.

In Table A9, all combinations that contain component clusters $1(\{1,3,6\})$ and 2 ( $\{2$, $4,5,7\}$ ) together have been deleted, as it is unlikely that these will be assigned to the same cell or machine. In the case of a long breakdown, some combination of clusters 1 and 2 may overlap and be assigned to the same cell or machine. The overlap information for this rare occurrence is in Table A8. For easy reading, Table A9 contains only the information concerning the numbers of slots required, but none on the numbers of tools required.

Table A9 provides a complete and concise set of tool duplication information, required for the algorithms of Section 4. The information on common and unique tooling and tool slot requirements is necessary for determining the maximum amount of potential pooling and partial pooling. This information also demonstrates the consequences, in terms of tool magazine capacity, of allocating various combinations of components to cells and then to machines.

For the six component clusters, Table A9 contains the information for all combinations of two, three, four, and five component clusters. For all these combinations, all tools can fit in the four primary magazines of two machines (which have a capacity of 240 slots). For all combinations of two component clusters and most combinations of three component clusters, all tools fit in the two primary magazines of only one machine. This means that for these latter combinations, all three machines in a cell can be pooled and identically tooled.

Table A7. Number of tools and slots taken by each component cluster

\begin{tabular}{lll}
\hline Component & Slots & Tools \\
\hline 1 & 64 & 38 \\
2 & 65 & 41 \\
3 & 38 & 26 \\
4 & 74 & 50 \\
5 & 16 & 10 \\
6 & 25 & 17 \\
\hline
\end{tabular}


Table A8. Number of tools and slots taken by various combinations of components: together, unique tools, and overlap

\begin{tabular}{|c|c|c|c|c|c|c|c|c|c|c|}
\hline \multicolumn{3}{|c|}{ Combination } & \multirow{2}{*}{$\frac{\begin{array}{l}\text { Tools/ } \\
\text { slots }\end{array}}{76 /}$} & \multirow{2}{*}{$\begin{array}{l}\text { Spec. } 1 \\
\text { tools } \\
\text { occup. } \\
35\end{array}$} & \multirow{2}{*}{$\begin{array}{l}\text { Spec. } 2 \\
\text { tools } \\
\text { occup. }\end{array}$} & \multirow[t]{2}{*}{$\begin{array}{l}\text { Spec. } 3 \\
\text { tools } \\
\text { occup. }\end{array}$} & \multirow[t]{2}{*}{$\begin{array}{l}\text { Spec. } 4 \\
\text { tools } \\
\text { occup. }\end{array}$} & \multirow[t]{2}{*}{$\begin{array}{l}\text { Spec. } 5 \\
\text { tools } \\
\text { occup. }\end{array}$} & \multirow[t]{2}{*}{$\begin{array}{l}\text { Spec. } 6 \\
\text { tools } \\
\text { occup. }\end{array}$} & \multirow{2}{*}{$\begin{array}{l}\begin{array}{l}\text { Common } \\
\text { tools } \\
\text { occup. }\end{array} \\
3\end{array}$} \\
\hline 1 & 2 & & & & & & & & & \\
\hline & & & 126 & 61 & 62 & & & & & 3 \\
\hline \multirow[t]{2}{*}{1} & 3 & & 621 & 36 & 24 & & & & & 2 \\
\hline & & & 100 & 62 & 36 & & & & & 2 \\
\hline \multirow[t]{2}{*}{1} & 4 & & $84 /$ & 34 & 46 & & & & & 4 \\
\hline & & & 134 & 60 & 70 & & & & & 4 \\
\hline \multirow[t]{2}{*}{1} & 5 & & $47 /$ & 37 & 9 & & & & & 1 \\
\hline & & & 79 & 63 & 15 & & & & & 1 \\
\hline \multirow[t]{2}{*}{1} & 6 & & $54 /$ & 37 & 16 & & & & & 1 \\
\hline & & & 88 & 63 & 24 & & & & & 1 \\
\hline \multirow[t]{2}{*}{2} & 3 & & $60 /$ & 34 & 19 & & & & & 7 \\
\hline & & & 92 & 54 & 27 & & & & & 11 \\
\hline \multirow[t]{2}{*}{2} & 4 & & 711 & 21 & 30 & & & & & 20 \\
\hline & & & 107 & 33 & 42 & & & & & 32 \\
\hline \multirow[t]{2}{*}{2} & 5 & & $49 /$ & 39 & 8 & & & & & 2 \\
\hline & & & 79 & 63 & 14 & & & & & 2 \\
\hline \multirow[t]{2}{*}{2} & 6 & & $53 /$ & 36 & 12 & & & & & 5 \\
\hline & & & 83 & 58 & 18 & & & & & 7 \\
\hline \multirow[t]{2}{*}{3} & 4 & & $69 /$ & 19 & 43 & & & & & 7 \\
\hline & & & 105 & 31 & 67 & & & & & 7 \\
\hline \multirow[t]{2}{*}{3} & 5 & & 341 & 24 & 8 & & & & & 2 \\
\hline & & & 52 & 36 & 14 & & & & & 2 \\
\hline \multirow[t]{2}{*}{3} & 6 & & 401 & 23 & 14 & & & & & 3 \\
\hline & & & 58 & 33 & 20 & & & & & 5 \\
\hline 4 & 5 & & 581 & 48 & 8 & & & & & 2 \\
\hline & & & 88 & 72 & 14 & & & & & 2 \\
\hline 4 & 6 & & $64 /$ & 47 & 14 & & & & & 3 \\
\hline & & & 96 & 71 & 22 & & & & & 3 \\
\hline 5 & 6 & & $25 /$ & 8 & 15 & & & & & 2 \\
\hline & & & 39 & 14 & 23 & & & & & 2 \\
\hline 1 & 2 & 3 & $94 /$ & 34 & 32 & 18 & & & & 1 \\
\hline & & & 152 & 60 & 52 & 26 & & & & 1 \\
\hline 1 & 2 & 4 & $104 /$ & 33 & 20 & 28 & & & & 2 \\
\hline & & & 166 & 59 & 32 & 40 & & & & 2 \\
\hline 1 & 2 & 5 & 841 & 35 & 37 & 8 & & & & 1 \\
\hline & & & 140 & 61 & 61 & 14 & & & & 1 \\
\hline 1 & 2 & 6 & 881 & 35 & 34 & 12 & & & & 1 \\
\hline & & & 144 & 61 & 56 & 18 & & & & 1 \\
\hline 1 & 3 & 4 & $103 /$ & 34 & 19 & 41 & & & & 2 \\
\hline & & & 165 & 60 & 31 & 65 & & & & 2 \\
\hline 1 & 3 & 5 & $70 /$ & 36 & 23 & 8 & & & & 1 \\
\hline & & & 114 & 62 & 35 & 14 & & & & 1 \\
\hline 1 & 3 & 6 & $76 /$ & 36 & 22 & 14 & & & & 1 \\
\hline & & & 120 & 62 & 32 & 20 & & & & 1 \\
\hline 1 & 4 & 5 & $92 /$ & 34 & 45 & 8 & & & & 1 \\
\hline & & & 148 & 60 & 69 & 14 & & & & 1 \\
\hline
\end{tabular}


Table A\& Number of tools and slots taken by various combinations of components: together, unique tools, and overlap (continued)

\begin{tabular}{|c|c|c|c|c|c|c|c|c|c|c|c|}
\hline \multicolumn{4}{|c|}{ Combination } & \multirow{2}{*}{$\begin{array}{l}\begin{array}{l}\text { Tools/ } \\
\text { slots }\end{array} \\
981\end{array}$} & \multirow{2}{*}{$\begin{array}{l}\text { Spec. } 1 \\
\text { tools } \\
\text { occup. } \\
34\end{array}$} & \multirow{2}{*}{$\begin{array}{l}\begin{array}{l}\text { Spec. } 2 \\
\text { tools }\end{array} \\
\text { occup. }\end{array}$} & \multirow{2}{*}{$\begin{array}{l}\text { Spec. } 3 \\
\text { tools } \\
\text { occup. } \\
14\end{array}$} & \multirow[t]{2}{*}{$\begin{array}{l}\text { Spec. } 4 \\
\text { tools } \\
\text { occup. }\end{array}$} & \multirow[t]{2}{*}{$\begin{array}{l}\text { Spec. } 5 \\
\text { tools } \\
\text { occup. }\end{array}$} & \multirow[t]{2}{*}{$\begin{array}{l}\text { Spec. } 6 \\
\text { tools } \\
\text { occup. }\end{array}$} & \multirow{2}{*}{$\begin{array}{l}\begin{array}{l}\text { Common } \\
\text { tools } \\
\text { occup. }\end{array} \\
1\end{array}$} \\
\hline 1 & 4 & 6 & & & & & & & & & \\
\hline & & & & 156 & 60 & 68 & 22 & & & & 1 \\
\hline \multirow[t]{2}{*}{1} & 5 & 6 & & $62 /$ & 37 & 8 & 15 & & & & 1 \\
\hline & & & & 102 & 63 & 14 & 23 & & & & 1 \\
\hline \multirow[t]{2}{*}{2} & 3 & 4 & & $88 /$ & 19 & 17 & 28 & & & & 5 \\
\hline & & & & 132 & 27 & 25 & 40 & & & & 5 \\
\hline \multirow[t]{2}{*}{2} & 3 & 5 & & $68 /$ & 34 & 19 & 8 & & & & 2 \\
\hline & & & & 106 & 54 & 27 & 14 & & & & 2 \\
\hline \multirow[t]{2}{*}{2} & 3 & 6 & & $72 /$ & 32 & 19 & 12 & & & & 3 \\
\hline & & & & 110 & 52 & 27 & 18 & & & & 5 \\
\hline 2 & 4 & 5 & & $79 /$ & 21 & 30 & 8 & & & & 2 \\
\hline & & & & 121 & 33 & 42 & 14 & & & & 2 \\
\hline \multirow[t]{2}{*}{2} & 4 & 6 & & $83 /$ & 19 & 30 & 12 & & & & 3 \\
\hline & & & & 125 & 29 & 42 & 18 & & & & 2 \\
\hline \multirow[t]{2}{*}{2} & 5 & 6 & & $61 /$ & 36 & 8 & 12 & & & & 2 \\
\hline & & & & 97 & 58 & 14 & 18 & & & & 2 \\
\hline \multirow[t]{2}{*}{3} & 4 & 5 & & $77 /$ & 19 & 43 & 8 & & & & 3 \\
\hline & & & & 119 & 31 & 67 & 14 & & & & 3 \\
\hline \multirow[t]{2}{*}{3} & 4 & 6 & & 821 & 18 & 42 & 13 & & & & 2 \\
\hline & & & & 124 & 28 & 66 & 19 & & & & 2 \\
\hline \multirow[t]{2}{*}{3} & 5 & 6 & & $48 /$ & 23 & 8 & 14 & & & & 2 \\
\hline & & & & 72 & 33 & 14 & 20 & & & & 2 \\
\hline \multirow[t]{2}{*}{4} & 5 & 6 & & $72 /$ & 47 & 8 & 14 & & & & 2 \\
\hline & & & & 110 & 71 & 14 & 22 & & & & 2 \\
\hline 1 & 2 & 3 & 4 & 121 & 33 & $: 8$ & 17 & 27 & & & 1 \\
\hline & & & & 192 & 59 & 26 & 25 & 39 & & & 1 \\
\hline 1 & 2 & 3 & 5 & $102 /$ & 34 & 32 & 18 & 8 & & & 1 \\
\hline & & & & 166 & 60 & 52 & 26 & 14 & & & 1 \\
\hline 1 & 2 & 3 & 6 & $106 /$ & 34 & 30 & 18 & 12 & & & 1 \\
\hline & & & & 170 & 60 & 50 & 26 & 18 & & & 1 \\
\hline 1 & 2 & 4 & 5 & $112 /$ & 33 & 20 & 28 & 8 & & & 1 \\
\hline & & & & 180 & 59 & 32 & 40 & 14 & & & 1 \\
\hline 1 & 2 & 4 & 6 & $116 /$ & 33 & 18 & 28 & 12 & & & 1 \\
\hline & & & & 184 & 59 & 28 & 40 & 18 & & & 1 \\
\hline 1 & 2 & 5 & 6 & $96 /$ & 35 & 34 & 8 & 12 & & & 1 \\
\hline & & & & 158 & 61 & 56 & 14 & 18 & & & 1 \\
\hline 1 & 3 & 4 & 5 & $111 /$ & 34 & 19 & 41 & 8 & & & 1 \\
\hline & & & & 179 & 60 & 31 & 65 & 14 & & & 1 \\
\hline 1 & 3 & 4 & 6 & $116 /$ & 34 & 18 & 40 & 13 & & & 1 \\
\hline & & & & 184 & 60 & 28 & 64 & 19 & & & 1 \\
\hline 1 & 3 & 5 & 6 & $84 /$ & 36 & 22 & 8 & 14 & & & 1 \\
\hline & & & & 134 & 62 & 32 & 14 & 20 & & & 1 \\
\hline 1 & 4 & 5 & 6 & $106 /$ & 34 & 44 & 8 & 14 & & & 1 \\
\hline & & & & 170 & 60 & 68 & 14 & 22 & & & 1 \\
\hline 2 & 3 & 4 & 5 & 961 & 19 & 17 & 28 & 8 & & & 2 \\
\hline & & & & 146 & 27 & 25 & 40 & 14 & & & 2 \\
\hline
\end{tabular}


Table A\& Number of tools and slots taken by various combinations of components: together, unique tools, and overlap (continued)

\begin{tabular}{|c|c|c|c|c|c|c|c|c|c|c|c|c|c|}
\hline \multicolumn{6}{|c|}{ Combination } & \multirow{3}{*}{$\begin{array}{l}\begin{array}{l}\text { Tools } / \\
\text { slots }\end{array} \\
100 / \\
150\end{array}$} & \multirow{2}{*}{$\begin{array}{l}\text { Spec. } 1 \\
\text { tools } \\
\text { occup. }\end{array}$} & \multirow{2}{*}{$\begin{array}{l}\begin{array}{l}\text { Spec. } 2 \\
\text { tools } \\
\text { occup. }\end{array} \\
17\end{array}$} & \multirow{2}{*}{$\begin{array}{l}\text { Spec. } 3 \\
\text { tools } \\
\text { occup. }\end{array}$} & \multirow{2}{*}{$\begin{array}{l}\begin{array}{l}\text { Spec. } 4 \\
\text { tools } \\
\text { occup. }\end{array} \\
12\end{array}$} & \multirow[t]{2}{*}{$\begin{array}{l}\text { Spec. } 5 \\
\text { tools } \\
\text { occup. }\end{array}$} & \multirow[t]{2}{*}{$\begin{array}{l}\text { Spec. } 6 \\
\text { tools } \\
\text { occup. }\end{array}$} & \multirow{2}{*}{$\begin{array}{l}\begin{array}{l}\text { Common } \\
\text { tools } \\
\text { occup. }\end{array} \\
2\end{array}$} \\
\hline 2 & 3 & 4 & 6 & & & & & & & & & & \\
\hline & & & & & & & 26 & 25 & 40 & 18 & & & 2 \\
\hline \multirow[t]{2}{*}{2} & 3 & 5 & 6 & & & $80 /$ & 32 & 19 & 8 & 12 & & & 2 \\
\hline & & & & & & 124 & 52 & 27 & 14 & 18 & & & 2 \\
\hline \multirow[t]{2}{*}{2} & 4 & 5 & 6 & & & $91 /$ & 19 & 30 & 8 & 12 & & & 2 \\
\hline & & & & & & 139 & 29 & 42 & 14 & 18 & & & 2 \\
\hline \multirow[t]{2}{*}{3} & 4 & 5 & 6 & & & $90 /$ & 18 & 42 & 8 & 13 & & & 2 \\
\hline & & & & & & 138 & 28 & 66 & 14 & 19 & & & 2 \\
\hline \multirow[t]{2}{*}{1} & 2 & 3 & 4 & 5 & & $129 /$ & 33 & 18 & 17 & 27 & 8 & & 1 \\
\hline & & & & & & 205 & 59 & 26 & 25 & 39 & 14 & & 1 \\
\hline \multirow[t]{2}{*}{1} & 2 & 3 & 4 & 6 & & $133 /$ & 33 & 17 & 17 & 27 & 12 & & 1 \\
\hline & & & & & & 209 & 59 & 25 & 25 & 39 & 18 & & 1 \\
\hline \multirow[t]{2}{*}{1} & 2 & 3 & 5 & 6 & & $114 /$ & 34 & 30 & 18 & 8 & 12 & & 1 \\
\hline & & & & & & 184 & 60 & 50 & 26 & 14 & 18 & & 1 \\
\hline \multirow[t]{2}{*}{1} & 2 & 4 & 5 & 6 & & 124 & 33 & 18 & 28 & 8 & 12 & & 1 \\
\hline & & & & & & 198 & 59 & 28 & 40 & 14 & 18 & & 1 \\
\hline \multirow[t]{2}{*}{1} & 3 & 4 & 5 & 6 & & 1241 & 34 & 18 & 40 & 8 & 13 & & 1 \\
\hline & & & & & & 198 & 60 & 28 & 64 & 14 & 19 & & 1 \\
\hline \multirow[t]{2}{*}{2} & 3 & 4 & 5 & 6 & & $108 /$ & 18 & 17 & 28 & 8 & 12 & & 2 \\
\hline & & & & & & 164 & 26 & 25 & 40 & 14 & 18 & & 2 \\
\hline \multirow[t]{2}{*}{1} & 2 & 3 & 4 & 5 & 6 & $141 /$ & 33 & 17 & 17 & 27 & 8 & 12 & 1 \\
\hline & & & & & & 223 & 59 & 25 & 25 & 39 & 14 & 18 & 1 \\
\hline
\end{tabular}

Table A9. Number of slots taken by combinations of components: together, unique tools, and common tools

\begin{tabular}{|c|c|c|c|c|c|c|c|c|}
\hline \multicolumn{2}{|c|}{ Combination } & \multirow{2}{*}{$\begin{array}{l}\text { Slots } \\
100\end{array}$} & \multirow{2}{*}{$\begin{array}{l}\text { Spec. } 1 \\
\text { slots }\end{array}$} & \multirow{2}{*}{$\begin{array}{l}\text { Spec. } 2 \\
\text { slots }\end{array}$} & \multirow[t]{2}{*}{$\begin{array}{l}\text { Spec. } 3 \\
\text { slots }\end{array}$} & \multirow[t]{2}{*}{$\begin{array}{l}\text { Spec. } 4 \\
\text { slots }\end{array}$} & \multirow[t]{2}{*}{$\begin{array}{l}\text { Spec. } 5 \\
\text { slots }\end{array}$} & \multirow{2}{*}{$\begin{array}{l}\begin{array}{l}\text { Common } \\
\text { slots }\end{array} \\
2\end{array}$} \\
\hline 1 & 3 & & & & & & & \\
\hline 1 & 4 & 134 & 60 & 70 & & & & 4 \\
\hline 1 & 5 & 79 & 63 & 15 & & & & 1 \\
\hline 1 & 6 & 88 & 63 & 24 & & & & 1 \\
\hline 2 & 3 & 92 & 54 & 27 & & & & 11 \\
\hline 2 & 4 & 107 & 33 & 42 & & & & 32 \\
\hline 2 & 5 & 79 & 63 & 14 & & & & 2 \\
\hline 2 & 6 & 83 & 58 & 18 & & & & 7 \\
\hline 3 & 4 & 105 & 31 & 67 & & & & 7 \\
\hline 3 & 5 & 59 & 36 & 14 & & & & 2 \\
\hline 3 & 6 & 58 & 33 & 20 & & & & 5 \\
\hline 4 & 5 & 88 & 72 & 14 & & & & 2 \\
\hline 4 & 6 & 96 & 71 & 22 & & & & 3 \\
\hline 5 & 6 & 39 & 14 & 23 & & & & 2 \\
\hline 1 & 4 & 165 & 60 & 31 & 65 & & & 2 \\
\hline 1 & 3 & 114 & 62 & 35 & 14 & & & 1 \\
\hline
\end{tabular}


Table A9. Number of slots taken by combinations of components: together, unique tools, and common tools (continued)

\begin{tabular}{|c|c|c|c|c|c|c|c|c|c|c|c|}
\hline \multicolumn{5}{|c|}{ Combination } & \multirow{2}{*}{$\frac{\text { Slots }}{120}$} & \multirow{2}{*}{$\begin{array}{l}\begin{array}{l}\text { Spec. 1 } \\
\text { slots }\end{array} \\
62\end{array}$} & \multirow{2}{*}{$\begin{array}{l}\begin{array}{l}\text { Spec. } 2 \\
\text { slots }\end{array} \\
32\end{array}$} & \multirow{2}{*}{$\begin{array}{l}\begin{array}{l}\text { Spec. } 3 \\
\text { slots }\end{array} \\
20\end{array}$} & \multirow[t]{2}{*}{$\begin{array}{l}\text { Spec. } 4 \\
\text { slots }\end{array}$} & \multirow[t]{2}{*}{$\begin{array}{l}\text { Spec. } 5 \\
\text { slots }\end{array}$} & \multirow{2}{*}{$\frac{\begin{array}{l}\text { Common } \\
\text { slots }\end{array}}{1}$} \\
\hline 1 & 3 & 6 & & & & & & & & & \\
\hline 1 & 4 & 5 & & & 148 & 60 & 69 & 14 & & & 1 \\
\hline 1 & 4 & 6 & & & 156 & 60 & 68 & 22 & & & 1 \\
\hline 1 & 5 & 6 & & & 102 & 63 & 14 & 23 & & & 1 \\
\hline 2 & 3 & 4 & & & 132 & 27 & 25 & 40 & & & 5 \\
\hline 2 & 3 & 5 & & & 106 & 54 & 27 & 14 & & & 2 \\
\hline 2 & 3 & 6 & & & 110 & 52 & 27 & 18 & & & 5 \\
\hline 2 & 4 & 5 & & & 121 & 33 & 42 & 14 & & & 2 \\
\hline 2 & 4 & 6 & & & 125 & 29 & 42 & 18 & & & 3 \\
\hline 2 & 5 & 6 & & & 97 & 58 & 14 & 18 & & & 2 \\
\hline 3 & 4 & 5 & & & 119 & 31 & 67 & 14 & & & 2 \\
\hline 3 & 4 & 6 & & & 124 & 28 & 66 & 19 & & & 2 \\
\hline 3 & 5 & 6 & & & 72 & 33 & 14 & 20 & & & 2 \\
\hline 4 & 5 & 6 & & & 110 & 71 & 14 & 22 & & & 2 \\
\hline 1 & 3 & 4 & 5 & & 179 & 60 & 31 & 65 & 14 & & 1 \\
\hline 1 & 3 & 4 & 6 & & 184 & 60 & 28 & 64 & 19 & & 1 \\
\hline 1 & 3 & 5 & 6 & & 134 & 62 & 32 & 14 & 20 & & 1 \\
\hline 1 & 4 & 5 & 6 & & 170 & 60 & 68 & 14 & 22 & & 1 \\
\hline 2 & 3 & 4 & 5 & & 146 & 27 & 25 & 40 & 14 & & 2 \\
\hline 2 & 3 & 4 & 6 & & 150 & 26 & 25 & 40 & 18 & & 2 \\
\hline 2 & 3 & 5 & 6 & & 124 & 52 & 27 & 14 & 18 & & 2 \\
\hline 2 & 4 & 5 & 6 & & 139 & 29 & 42 & 14 & 18 & & 2 \\
\hline 3 & 4 & 5 & 6 & & 138 & 28 & 66 & 14 & 19 & & 2 \\
\hline 1 & 3 & 4 & 5 & 6 & 198 & 60 & 28 & 64 & 14 & 19 & 1 \\
\hline 2 & 3 & 4 & 5 & 6 & 164 & 26 & 25 & 40 & 14 & 18 & 2 \\
\hline
\end{tabular}

Since so much pooling can be done, it appears that formulations $\mathrm{P}$ and $\mathbf{P} 2$ are essentially linear, in practice. Each day, components can be allocated to cells and to the machines to balance workloads, without the need to consider tool magazine capacity constraints.

However, recall that the data are not complete. There is no information yet on the tools required to machine components 2 and 8 . Additional tools may also be required to process the other components. Additional gearbox components may be machined on the FMS in the future. As further information is obtained or new part types introduced into the FMS, these tables can be updated. If more tools are required, the tool magazine capacity will be tighter, and less pooling will be possible. This is the reason why the formulations of Section 4 needed to be in a very general form.

In addition, some tools may be used often enough so that several copies of each may need to be loaded into the tool magazines. Cutting time for tools such as these may be high. There is no information yet on the amount of sister tooling required. This information could potentially reduce the amount of pooling that could be done, since more space in the magazines would be required for the sisters. Since cutting time/cutter is small for aluminum parts, placement in the tool magazine may also be important. 
In the case of breakdowns, there may be either capacity problems or workload balance problems. If machines are pooled, shifting workload is easy and is a linear program. If this is not enough to solve the problem, some components (and hence some tools) may have to be shifted from cell to cell or from machine to machine. The information of Table A9 and the total processing time requirements of each component are all that is needed to help make such reallocation decisions. These decisions can then be made manually. If some workload has to be shifted, for various potential reallocations to machines or cells, Table A9 contains the total number of tool slots required; the number of new tool slots required; and for formulation $\mathrm{P} 1$, the tool overlap as the new component(s) are included in the same magazine with the old.

\section{Acknowledgments}

This research was done while the author was at the Automation Division of COMAU in Torino, Italy.

I would like to thank Giovanni Maria Secco-Suardo of COMAU for helpful discussions during the development of the algorithms. Marzia Brunetto is gratefully thanked for her help in developing the programs for component clustering and tool overlap that provide some of the results in the Appendix. COMAU is acknowledged for their support during this work. Finally, Rajan Suri, Avi Seidmann, and anonymous referees are thanked for their careful reading and thoughtful suggestions to improve an earlier version of this article.

\section{References}

Berrada, Mohammed, and Stecke, Kathryn E, "A Branch-and-Bound Approach for Machine Load Balancing in Flexible Manufacturing Systems," Management Science, Vol. 32, No. 10, pp. 1316-1335 (October 1986).

Carrie, Alan S., and Perera, D.T.S., "Work Scheduling in FMS under Tool Availability Constraints," International Journal of Production Research, Vol. 24, No. 6, pp. 1299-1308 (1986).

Cavaillé, Jean-Bernard, and Dubois, Didier, "Heuristic Methods Based on Mean-Value Analysis for Flexible Manufacturing Systems Performance Evaluation," Proceedings of the 2Ist IEEE Conference on Decision and Control, Orlando, Florida, pp. 1061-1065 (December 1982).

Hwang, Syming, "Part Selection Problems in Flexible Manufacturing Systems Planning Stage," Proceedings of the Second ORSA/TIMS Conference on Flexible Manufacturing Systems: Operations Research Models and Applications, Ann Arbor, Michigan, K.E. Stecke and R. Suri (editors), Elsevier Science Publishers B.V., Amsterdam, pp. 297-309 (August 12-15, 1986).

Johnson, D. S., "Near Optimal Bin Packing Algorithms," Ph.D. dissertation, M.I.T., Mathematics Department, Cambridge, Mass. (1973)

Menga, Giuseppe; Bruno, G.; Conterno, Renato; and Actis Dato, M., "Modeling FMS by Closed Queueing Network Analysis Methods," IEEE Transactions on Components, Hybrids, and Manufacturing, CHM-7, No. 3, pp. 3-12 (September 1984).

Reiser, M., and Lavenberg, S. S., "Mean-Value Analysis of Closed Multichain Queueing Networks," Journal of the Association for Computing Machinery, Vol. 27, No. 2, pp. 313-322 (April 1980).

Schrage, Linus E., Linear Programming Models with LINDO, The Scientific Press, Palo Alto, Calif. (1981).

Stecke, Kathryn E., "A Hicrarchical Approach to Solving Machine Grouping and Loading Problems of Flexible Manufacturing Systems," European Journal of Operational Research, Vol. 24, No. 3, pp. 369-378 (March 1985). 
Stecke, Kathryn E., "Formulation and Solution of Nonlinear Integer Production Planning Problems for Flexible Manufacturing Systems," Management Science, Vol. 29, No. 3, pp. 273-288 (March 1983).

Stecke, Kathryn E., and Talbot, F. Brian, "Heuristics for Loading Flexible Manufacturing Systems," Flexible Manufacturing: Recent Developments in FMS, Robotics, CAD/CAM, CIM, A. Raouf and S. I. Ahmad (editors), Elsevier Science Publishers B.V., Amsterdam, pp. 73-84 (1985).

Suri, Rajan, and Hildebrandt, Richard R., "Modeling Flexible Manufacturing Systems Using Mean Value Analysis," Journal of Manufacturing Systems, Vol. 3, No. 1, pp. 27-38 (January 1984). 